\title{
Exploiting the Mechanical Bond for Molecular Recognition and Sensing of Charged Species
}

\author{
Krzysztof M. Bąk, ${ }^{a, b}$ Kyriakos Porfyrakis, ${ }^{b}$ Jason J. Davis ${ }^{c}$ and Paul D. Beer ${ }^{a, *}$ \\ The unique properties of the mechanical bond have been increasingly used for the purpose of molecular recognition. The \\ recent progress in the development of cation and anion template strategies for the construction of mechanically interlocked \\ molecules (MIMs) have resulted in a variety of ion binding catenanes and rotaxanes host structures. The appropriate \\ integration of reporting redox- and photo-active centres into their structural frameworks can result in prototype molecular \\ sensors for target charged species and molecular switches for potential nanotechnological applications. This review presents \\ progress in the field of MIM hosts for ion recognition and sensing since 2014, focusing on the synthetic approaches employed \\ and mechanisms of host-guest binding and detection.
}

\section{Introduction}

Mechanically interlocked molecules (MIMs) such as rotaxanes and catenanes have been the subject of intense research due to their non-trivial topology and unique dynamic properties which can be exploited in an ever increasing range of applications. ${ }^{1-10}$ In recent years their potential in molecular guest recognition has also been realised. Various template strategies facilitate the synthesis of MIMs containing unique three dimensional cavities decorated with complementary donor/acceptor motifs required for the selective binding of a target guest species. ${ }^{11-15}$ Many interlocked structures have proved to be excellent molecular hosts displaying notably enhanced selectivity in comparison to analogous non-interlocked systems. ${ }^{16}$ The incorporation of redox-active and photo-active reporting groups within such MIM hosts results in optical and/or electrochemical guest sensing capabilities. ${ }^{17}$ Moreover, successful recognition provides a means of control for the relative positions of interlocked components (co-conformation) in molecular switches.

In this article we focus on the progress in the development of ion binding and sensing MIMs since the last reviews on this subject in 2014. ${ }^{18-20}$ Firstly, we discuss cation binding MIM host structures which remain in the minority, despite the popularity of metal-directed strategies employed in the synthesis of interlocked structures. Secondly, attention is turned to anion binding MIMs, which has been a research topic of special interest in our group.

a. Chemistry Research Laboratory, Department of Chemistry, University of Oxford Mansfield Road, Oxford, OX1 3TA, UK.E-mail: paul.beer@chem.ox.ac.uk b. Department of Materials, University of Oxford, Parks Road, Oxford, OX1 3PH, UK

c. Physical \& Theoretical Chemistry Laboratory, South Parks Road, Oxford, OX1 3TA, UK

\section{Mechanically Interlocked Molecules for Cation} Recognition, Sensing

Metal templated synthesis of MIMs, pioneered by Sauvage has become one of the most powerful tools for the formation of mechanical bonds. ${ }^{21}$ Removal of the template, typically a transition metal, provides a well-defined cavity in which the cation can be bound again. This passive template methodology usually leads to interlocked host structures which coordinatively saturate a bound metal. In 2006, Leigh and coworkers demonstrated another approach for the synthesis of MIMs, relying on a kinetic metal templating effect. ${ }^{22}$ In this active metal template (AMT) strategy, a transition metal cation plays a dual role of a template, typically bound within the cavity of a macrocycle, and a catalyst of the reaction leading to the formation of the mechanical bond. These two approaches are the most common methods employed in the synthesis of various MIM host structures capable of transition metal cation recognition.

Goldup, Roessler and co-workers used an active template variant of $\mathrm{Cu}(\mathrm{I})$-mediated alkyne-azide cycloaddition (CUAAC) to obtain a series of [2] rotaxanes 1-3 with an increasing number of $\mathrm{N}$ donors within the interlocked cavity (Fig. 1). ${ }^{23}$ Binding studies with transition metal ions such as $\mathrm{CO}^{2+}, \mathrm{Ni}^{2+}, \mathrm{Cu}^{2+}$ and $\mathrm{Zn}^{2+}$ revealed that the mechanical bond not only enhanced thermodynamic stability but also enforced unusual coordination geometries of the metals, inaccessible with analogous non-interlocked ligands. Rotaxane 3, for example, formed unprecedented five-coordinate $\mathrm{Co}^{2+}$ and $\mathrm{Ni}^{2+}$ complexes in the solid state and solution as a result of the exclusion of additional ligands due to steric hindrance imbued by the rotaxane's binding pocket. In addition, as demonstrated by Sauvage in his original phenanthroline containing [2]catenanes, ${ }^{24}$ the metal's redox properties were shown to be significantly altered. For example electrochemical stability of 3. $\mathrm{Cu}^{2+}$ complex was dramatically increased in comparison to the 

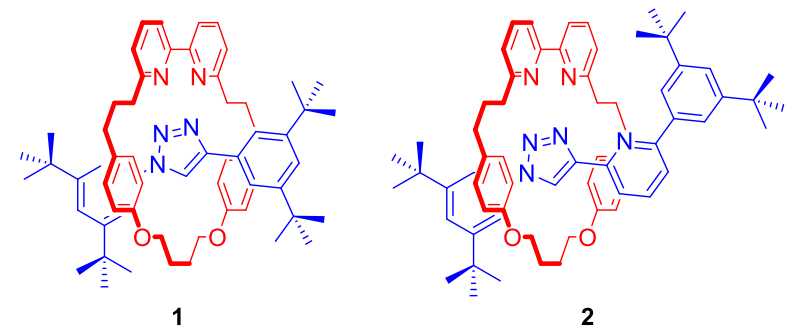

1

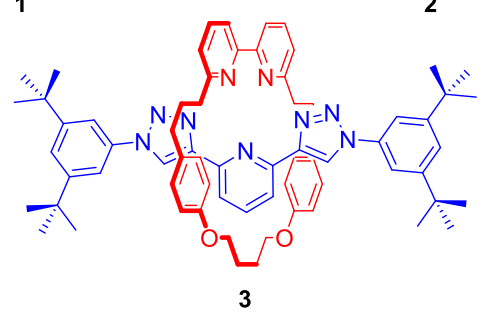

3

Figure 1 Goldup and Roessler's rotaxane hosts 1-3 for recognition of transition metals.

non-interlocked analogue, by preventing drastic reorganisation of ligands.

In many cases the binding cavities of MIMs are not static and are able to reorganise to encapsulate various guests. In an elegant example, Loeb prepared a [2]rotaxane 4 containing a bis-benzimidazole axle component (Fig. 2) by a hydrogen bond template ring-closing metathesis (RCM) of a crown ether macrocyclic precursor. ${ }^{25}$ Addition of metal cations with different coordination preferences such as $\mathrm{Cu}^{+}$and $\mathrm{Li}^{+}$resulted in a rotation of the macrocyclic component around the axle to access the most suitable set of donors in solution and in the solid state. In the case of $\mathrm{Cu}^{+}$the olefin moiety of the macrocycle was directly involved in cation binding. Whilst, in the case of $\mathrm{Li}^{+}$, the macrocycle was bound to the cation only via oxygen atoms. Further studies of this system showed that $\mathrm{Ag}^{+}$ can lead to remarkably different co-conformations of $\mathbf{4}$ in the solid state. ${ }^{26}$
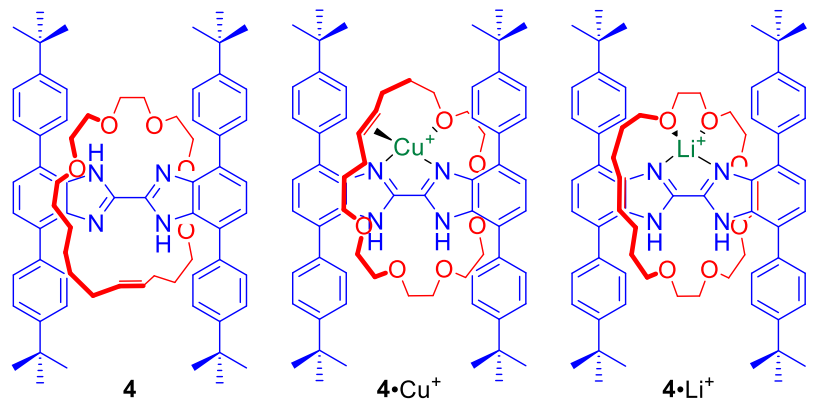

Figure 2 Loeb's rotaxane 4 and its complexes with $\mathrm{Li}^{+}$and $\mathrm{Cu}^{+}$

Attaching a reporting group in close proximity to a binding pocket is a common approach to obtain ion sensing MIMs. For example Goldup, Watkinson and co-workers used the AMTCUAAC strategy to obtain a series of [2] rotaxanes containing a fluorescent 1,8-naphtalimide derivative in the axle component (Fig. 3). ${ }^{27}$ It was found that the nature of the metal cation guest led to profound changes in the rotaxanes' optical sensing behaviour. For instance, rotaxane 5 displayed a selective switchon response upon $\mathrm{Hg}^{2+}$ binding, while 6 was selective for $\mathrm{Zn}^{2+}$ over various other transition metal cations including $\mathrm{Cd}^{2+}$ in $\mathrm{MeCN} / \mathrm{H}_{2} \mathrm{O}$ 98:2. Solid state studies suggested that the optical
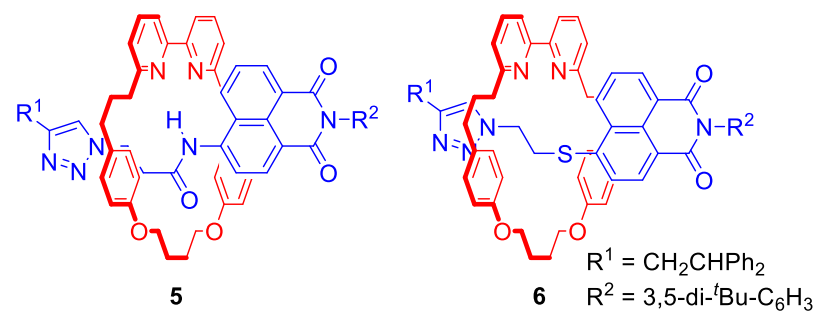

Figure 3 [2] Rotaxanes containing fluorescent 1,8-naphthalimide derivative in the axle component.

response was the result of altering macrocycle position relative to fluorophore upon binding inside the cavity. Importantly, the cavity had substantial influence over binding selectivity.

Another approach to transition metal sensing was explored by Lin and co-workers who obtained rotaxane 7 (Fig. 4) by stoppering of a $\mathrm{Pd}^{2+}$ templated pseudorotaxane. ${ }^{28}$ One of its stopper components consisted of a tetraphenylethylene moiety which is known for exhibiting strong aggregation induced emission (AIE) behaviour. For that reason, in the presence of more than $20 \%$ of water, rotaxane 7 generated a bright blue emission. Interestingly, it was selectively quenched by the addition of $\mathrm{Fe}^{3+}$ in contrast to various alkali and other transition metal ions. Additionally, emission quenching of the axle component by $\mathrm{Fe}^{3+}$ in the same solvent was significantly weaker. The authors claimed that this difference in behaviour was caused by the formation of the 1:1 stoichiometric complex between rotaxane 7 and $\mathrm{Fe}^{3+}$ due to the binding inside the cavity, which prevented aggregation.

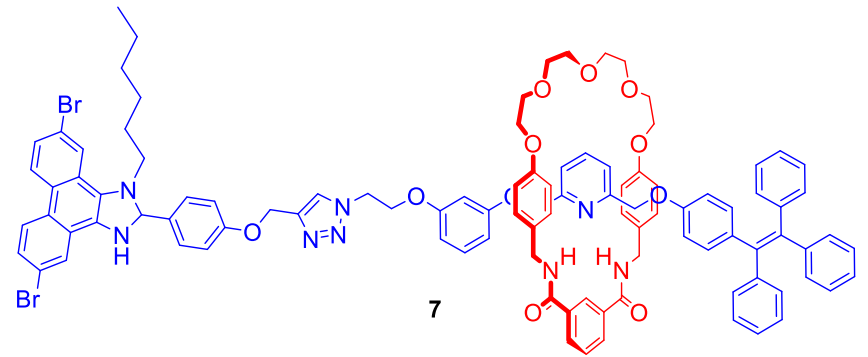

Figure 4 [2]Rotaxane exhibiting aggregation induced emission behaviour.

Leung and co-workers used fluorescent [2]rotaxanes 8 and 9 for sensing of trivalent transition metals, particularly $\mathrm{Au}^{3+}$ (Fig. 5). ${ }^{29}$ The axle components of this system were stoppered with fluorophores, such as anthracene or BODIPY, whose fluorescence was quenched via photoinduced electron transfer (PET) by proximal macrocyclic components. Importantly, the dynamic behaviour of the imine bonds of macrocyclic components allowed for metal induced hydrolysis of the rings,
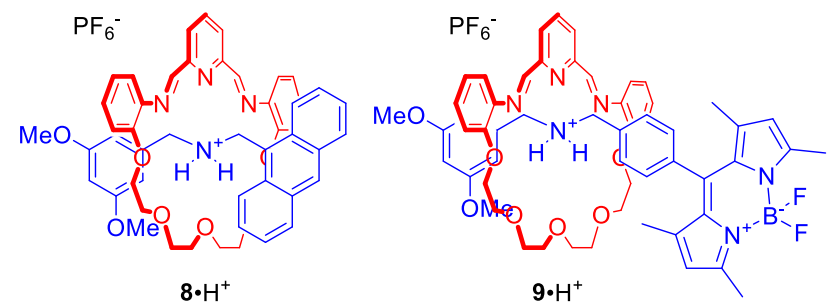

Figure 5 [2]Rotaxanes sensing $\mathrm{Au}^{3+}$ due to metal induced release of the axle component. 
releasing the axle component and producing a turn-on fluorescent response. Interestingly, reduction of imine bonds to amine led to [2] rotaxanes which exhibited a strong turn-on fluorescent response upon addition of $\mathrm{Au}^{3+}$. The authors claimed that this behaviour was caused by the metal being encapsulated within the cavity of the rotaxanes.

Although lanthanides have been exploited as metal templates in the synthesis of catenanes, ${ }^{30}$ rotaxanes $^{31}$ and molecular knots, ${ }^{32,33}$ their recognition by MIMs has only been recently investigated. Ghosh and co-workers used $\mathrm{Cu}(\mathrm{I})$ to template the formation of [2]catenane $\mathbf{1 0}$ which was shown to bind lanthanide metal ions such as $\mathrm{Eu}^{3+}$ and $\mathrm{Gd}^{3+}$ via coordination to phenanthroline and ester groups inside an interlocked cavity formed by two macrocycles, leading to the increase of photoluminescence intensity of lanthanides in solution (Fig. 6). ${ }^{34}$

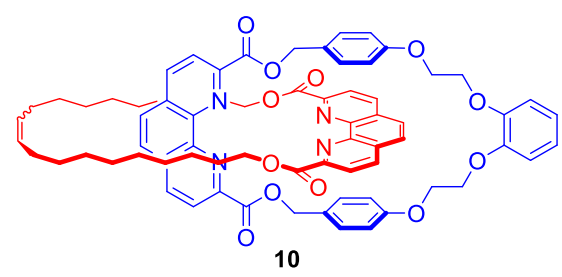

Figure 6 [2]Catenane host for lanthanides recognition.

The interlocked nature of catenanes and rotaxanes provide an attractive environment for enantioselective binding. Niemeyer and co-workers obtained [2]catenane (S,S)-11 containing a BINOL-phosphate motif (Fig. 7) via ring closing metathesis of a $\mathrm{Ca}^{2+}$ templated orthogonal complex. ${ }^{35}$ The tetrabutylammonium (TBA) salt of $\mathbf{1 1}$ bound various doubly protonated chiral diamines such as $\mathrm{C}$-protected amino acids LysOMe and Arg-OMe, or 1,2-diaminocyclohexane (DACH) in $d_{6}$ DMSO. Most importantly, [2]catenane 11 exhibited a significantly higher degree of stereodiscrimination between enantiomers than its macrocyclic component demonstrating that incorporation of chiral bulky groups adjacent to the binding cavity of MIM is an effective strategy for the design of enantioselective receptors.

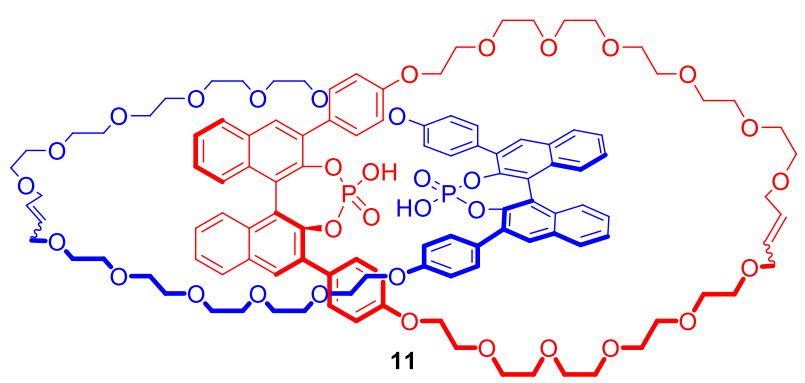

Figure 7 [2]Catenane host capable of enantioselective recognition.

Although not directly related to the subject of this review, it is difficult not to mention that cation binding MIMs have emerged as promising ligands in various transition metal catalysed reactions or even as catalysts themselves. For example, Leigh's group reported [2]rotaxane 12 containing a

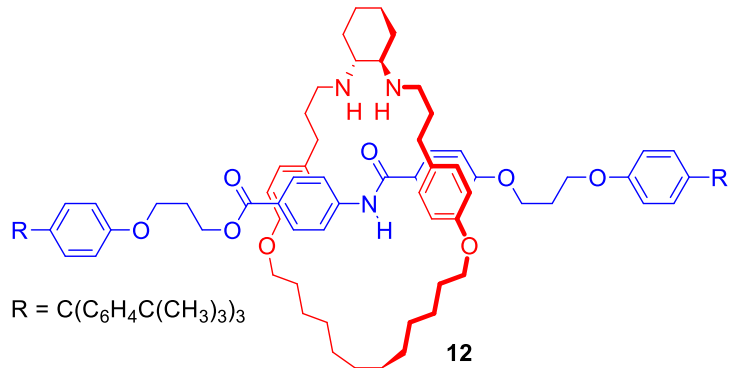

Figure 8 [2]Rotaxane ligand for $\mathrm{Ni}^{2+}$ catalysed Michael addition.

chiral trans-N, $\mathrm{N}^{\prime}$-dialkyl-1,2-cyclohexanediamine macrocycle (Fig. 8), which endotopically coordinates $\mathrm{Cu}^{+}$during active metal Goldberg formation of $\mathrm{C}-\mathrm{N}$ bond. ${ }^{36}$ The interlocked ligand was used in $\mathrm{Ni}^{2+}$ catalysed enantioselective Michael addition of diethyl malonate to trans- $\beta$-styrene with good yield (>98\% conversion) and enantioselectivity (93:7 enantiomeric ratio) reported.

Goldup and co-workers presented a catalytic [2]rotaxane 13 (Fig. 9) which required a $\mathrm{Cu}(\mathrm{I})$ cofactor to induce activity in a gold-catalysed cyclopropanation reaction. ${ }^{37}$ The authors suggested that copper coordination to a bipyrydyl moiety interrupted the interaction of the macrocycle with the axle incorporated $\mathrm{Au}^{+}$catalytic centre which was responsible for hampering its activity. Further work on this system allowed the Goldup group to obtain a mechanically planar chiral ligand $\mathbf{1 4}$ (Fig. 9) for the enantioselective variant of cyclopropanation. Stereoselectivities observed in the presence of rotaxane $\mathbf{1 4}$ were comparable with a conventional covalent catalyst demonstrating the unexplored potential of mechanical chirality in enantioselective catalysis. ${ }^{38}$

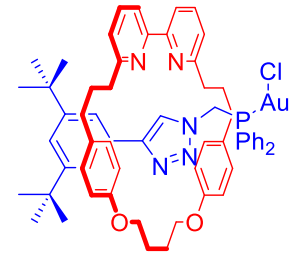

13

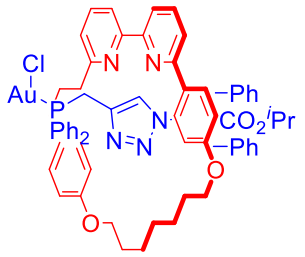

14
Figure 9 [2]Rotaxanes exhibiting catalytic activity upon $\mathrm{Cu}^{+}$complexation.

Chen, Chiu and co-workers prepared [2]rotaxane 15 (Scheme 1) with cation-induced catalytic properties via alkali metal ion templated clipping of an imino macrocycle and subsequent reduction. ${ }^{39} \mathrm{In}$ its free state, $\mathbf{1 5}$ was not able to catalyse the Michael addition of diethyl malonate to nitrostyrene. However, upon complexation with $\mathrm{Na}^{+}$its activity was immediately turned on. Interestingly, the authors reported that they were able to stop and restart the reaction by alternate additions of $\mathrm{NaBAr}_{4}$ and [2.2.2]cryptand sequestering $\mathrm{Na}^{+}$. In the noncomplexed state, $\mathbf{1 5}$ adopted conformations in which the oxygen atoms of the macrocyclic component formed hydrogen bonds with the amide proton located on the axle. Binding of a sodium cation resulted in a rotation of the ring to the co-conformation in which $\mathrm{Na}^{+}$was simultaneously bound by the crown ether oxygens of the macrocycle and amide carbonyl 

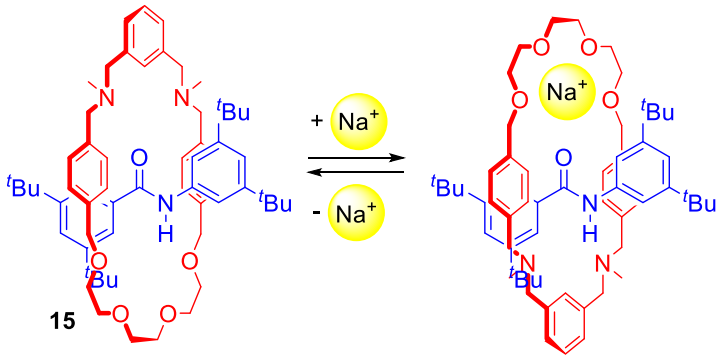

Scheme 1 [2]Rotaxane catalyst activated by $\mathrm{Na}^{+}$recognition.

of the axle (Scheme 1). This change enabled the activation of styrene in a newly formed cavity on the other side of the axle.

The examples presented above show the breadth of potential applications for cation binding interlocked structures. The unique cavities provide the environment required for selective binding of various metal cations and larger chiral guests. For this reason cation-binding MIMs are excellent platforms for the construction of selective optical sensors and more recently promising candidates for novel catalysts.

\section{Mechanically Interlocked Molecules for Anion Recognition and Sensing}

The selective binding of anions represents a significant scientific challenge due to their intrinsic properties such as complex geometries, low charge densities, $\mathrm{pH}$-dependency and high hydration energies. At the same time anionic species play important roles in environmental, industrial and biological processes, which require methods for their detection and sequestering by artificial systems. ${ }^{40,41}$ During the past few decades, a plethora of acyclic and macrocyclic receptors capable of anion binding have been reported. In an effort to raise the bar in anion selectivity, we sought to exploit the potential of the unique three-dimensional binding cavities of MIMs for anion recognition and sensing applications.

In 2001 our group demonstrated the formation of an orthogonal complex assembly between a hydrogen bond donating 3,5-bis-amide pyridinium group and a neutral isophthalamide motif via chloride anion coordination. ${ }^{42}$ Since then this anion template strategy has been employed in the synthesis of numerous interlocked structures, which importantly were demonstrated to bind anions with increased thermodynamic stability and selectivity in comparison to noninterlocked macrocyclic or acyclic receptor homologues. The vast majority of these MIMs bound anions via hydrogen bonds (HBs). In more recent years, halogen bonding (XB), the attractive interaction between an electron-deficient halogen atom and a Lewis base, has been used in anion host design. ${ }^{43-45}$ The comparable strength to $\mathrm{HB}$ and stringent linear directionality has made the $X B$ interaction a particularly valuable tool in solid state crystal engineering and materials chemistry. Notably however, exploiting halogen bonding in the solution phase has proved to be an effective strategy for anion recognition particularly in highly competitive aqueous media. Indeed, anion recognition in water remains a key challenge in modern anion supramolecular chemistry ${ }^{46-49}$ and our group has constructed various MIMs incorporating halogen bond donors which demonstrate this capability. For the purpose of this review, the following examples of anion binding MIMs are divided into three main categories dictated by the non-covalent interactions used to achieve anion recognition: hydrogen bonding systems, mixed hydrogen-halogen bonding systems, and systems dominated by halogen bonding.

\section{HB MIM host systems}

The majority of MIMs prepared via the anion templation protocol have used chloride as the template. However, synthesis of [2] catenane $\mathbf{1 6} \cdot \mathrm{NO}_{3}$ (Fig. 10) via RCM was an unprecedented example of using a nitrate anion template. ${ }^{50}$ Nitrate recognition by host systems is difficult due to its complex trigonal planar geometry, low affinity for hydrogen bond donors and relatively strong solvation, hence it is rarely used as a template. Importantly, the complementary tridentate binding cavity of $\mathbf{1 6} \cdot \mathrm{PF}_{6}$ was selective for nitrate over a range of mono-charged oxoanions, while its association constant value for $\mathrm{NO}_{3}{ }^{-}$was slightly higher than for $\mathrm{Cl}^{-}$in $\mathrm{CDCl}_{3} / \mathrm{CD}_{3} \mathrm{OD} / \mathrm{D}_{2} \mathrm{O}$ $45: 45: 10$. Nitrate templation was also successfully used in the synthesis of [2] rotaxane $17 \cdot 2 \mathrm{PF}_{6} .{ }^{51}$ This doubly charged bistriazole MIM bound nitrate even more strongly than $16 \cdot \mathrm{PF}_{6}$ due

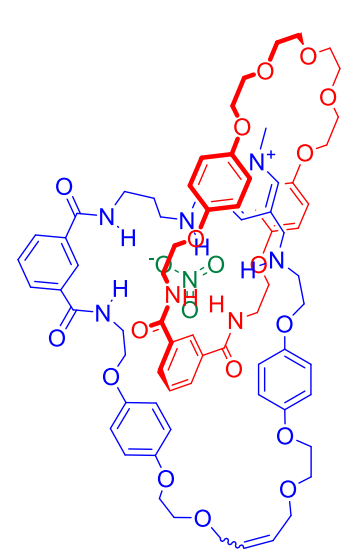

$16 \cdot \mathrm{NO}_{3}$

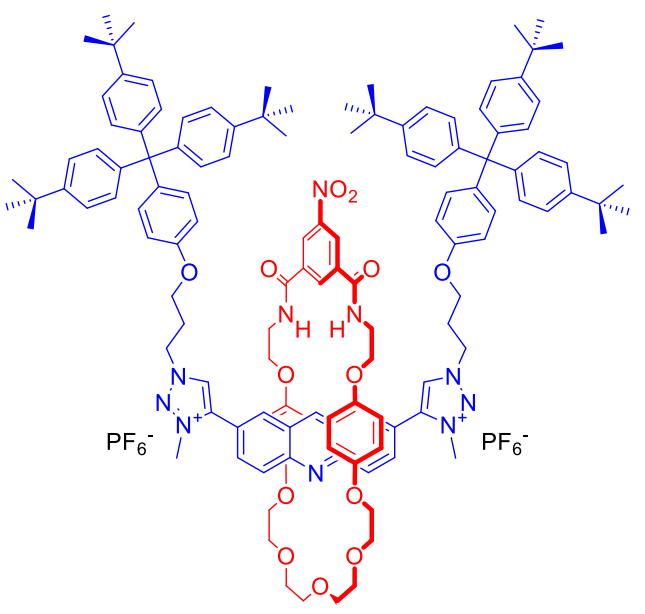

$17 \cdot 2 \mathrm{PF}_{6}$

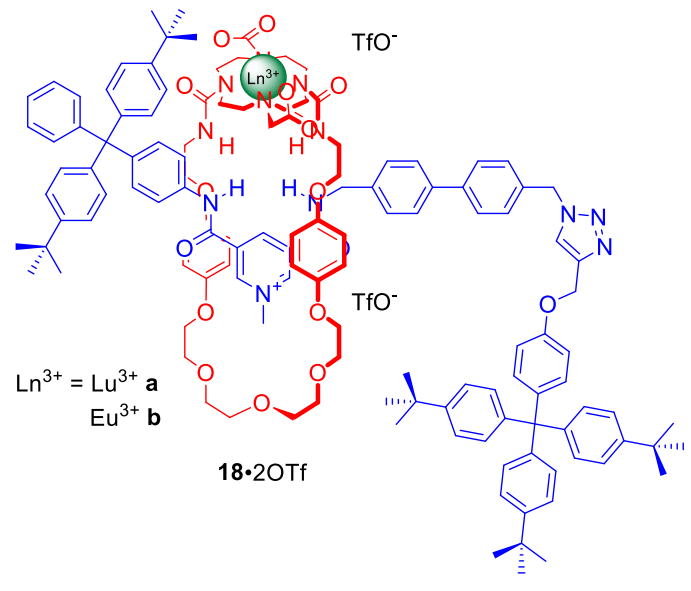

Figure 10 Interlocked structures for nitrate $(\mathbf{1 6}, \mathbf{1 7})$ and nitrite recognition (18). 

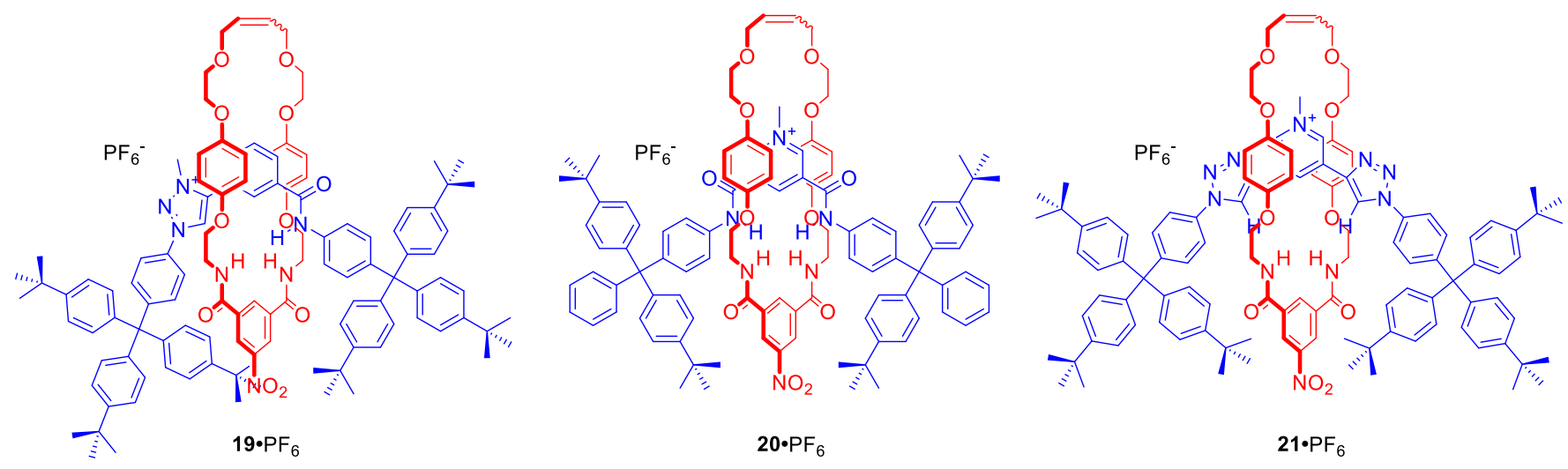

Figure 11 Anion binding MIMs incorporating iodotriazoloum and/or pyridinium motif.

to increased double charge, however the degree of selectivity over halides was lower.

Binding of nitrite anion by molecular hosts is even more uncommon than that of nitrate. Nevertheless $\mathrm{NO}_{2}{ }^{-}$was used as a unique template, exploiting direct anion-lanthanide coordination in concert with $\mathrm{HB}$, in the synthesis of luminescent [2] rotaxanes 18a-20Tf and 18b-20Tf in ca. $50 \%$ yields (Fig. 10). ${ }^{52}$ Monitoring the photophysical behaviour of the DOTA encapsulated europium cation enabled selective luminescence sensing of fluoride in $\left(\mathrm{CH}_{3}\right)_{2} \mathrm{CO} / \mathrm{H}_{2} \mathrm{O} 99: 1$. Binding of $\mathrm{F}^{-}$led to a drastic emission quenching due to direct coordination of the halide anion to the metal centre and a displacement of water from the inner coordination sphere of the metal. In contrast, acetate and nitrite caused only moderate quenching while the addition of chloride led to no changes of the lanthanide emission.

Among many MIMs obtained via chloride templation are various structures containing polarized $\mathrm{C}-\mathrm{H}$ hydrogen bond donors such as triazole or triazolium moieties. [2]Rotaxane 19. $\mathrm{PF}_{6}$ (Fig. 11) was designed to incorporate amide and triazolium functionalities in the axle component. ${ }^{53}$ The resulting interlocked host demonstrated halide selectivity $\left(\mathrm{Cl}^{-}>\mathrm{Br}^{-}\right)$over oxoanions such as $\mathrm{H}_{2} \mathrm{PO}_{4}^{-}$or $\mathrm{AcO}^{-}$in $\mathrm{CDCl}_{3} / \mathrm{CD}_{3} \mathrm{OD}$ 1:1. Importantly, this selectivity was more pronounced than in the cases of analogous rotaxanes $\mathbf{2 0} \cdot \mathrm{PF}_{6}$ or $\mathbf{2 1} \cdot \mathrm{PF}_{6}$ incorporating pyridinium bis-amide or pyridinium bis-triazole axle components.

Most of the anion binding interlocked hosts obtained via anion templation have been positively charged. 22a-d were the first neutral redox-active [2]rotaxanes containing a ferroceneappended macrocycle unit enabling sensing by means of electrochemical methodologies (Fig. 12). ${ }^{54}$ These rotaxanes were capable of binding halides $\left(\mathrm{Cl}^{-}>\mathrm{Br}^{-}>\mathrm{I}^{-}\right)$over $\mathrm{H}_{2} \mathrm{PO}_{4}^{-}$or $\mathrm{AcO}^{-}$ in competitive $\mathrm{CDCl}_{3} / \mathrm{CD}_{3} \mathrm{OD} / \mathrm{D}_{2} \mathrm{O} 45: 45: 10$ solvent mixture and detecting chloride via a significant cathodic shift of the ferrocene/ferrocenium redox couple.

Metalloporphyrins have been utilised as optically responsive reporter groups in interlocked hosts such as anion binding [2]catenane 23. $\mathrm{PF}_{6}$ (Fig. 13). ${ }^{55}$ The solid state structure of 23. $\mathrm{PF}_{6}$ clearly demonstrated that the pyridine-zinc coordinate bond within the interlocked structure preorganizes the anion binding cavity for chloride recognition. Interestingly, despite the considerable chloride affinity only modest

detectable changes in the metalloporphyrin component's UV/Vis and fluorescence spectra were observed.

Anion template directed synthesis is not the only method of producing anion binding MIMs. Jolliffe and Goldup used the active metal template strategy to obtain fluorescent [2] rotaxane $\mathbf{2 4}$ containing a urea motif directly linked to a

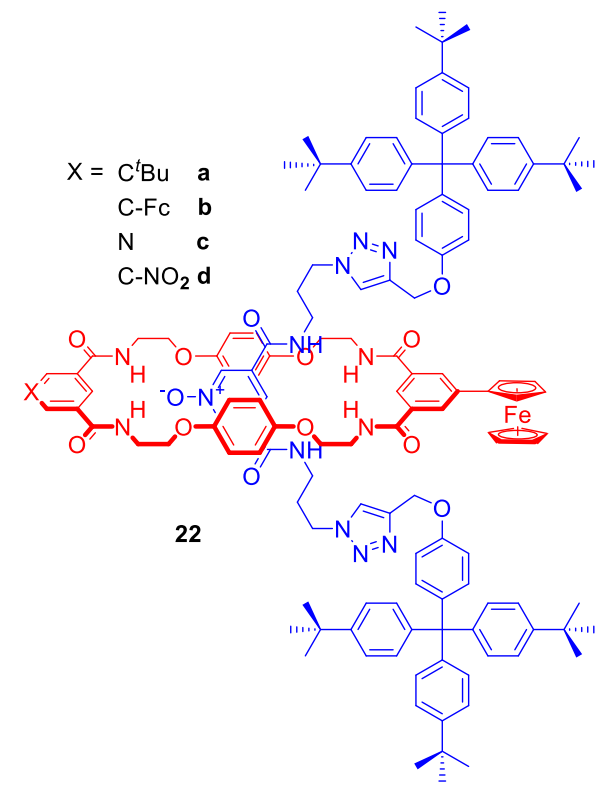

Figure 12 Neutral redox-active [2]rotaxanes.

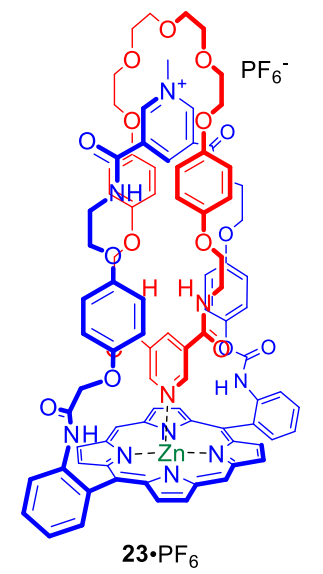

Figure 13 Metalloporphyrin containing [2]catenane. 


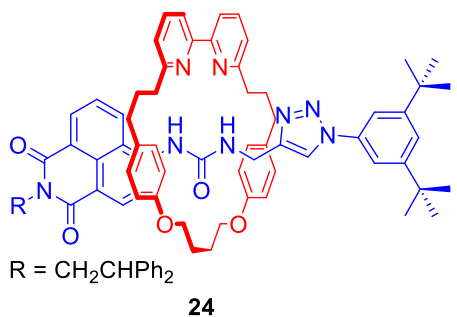

24

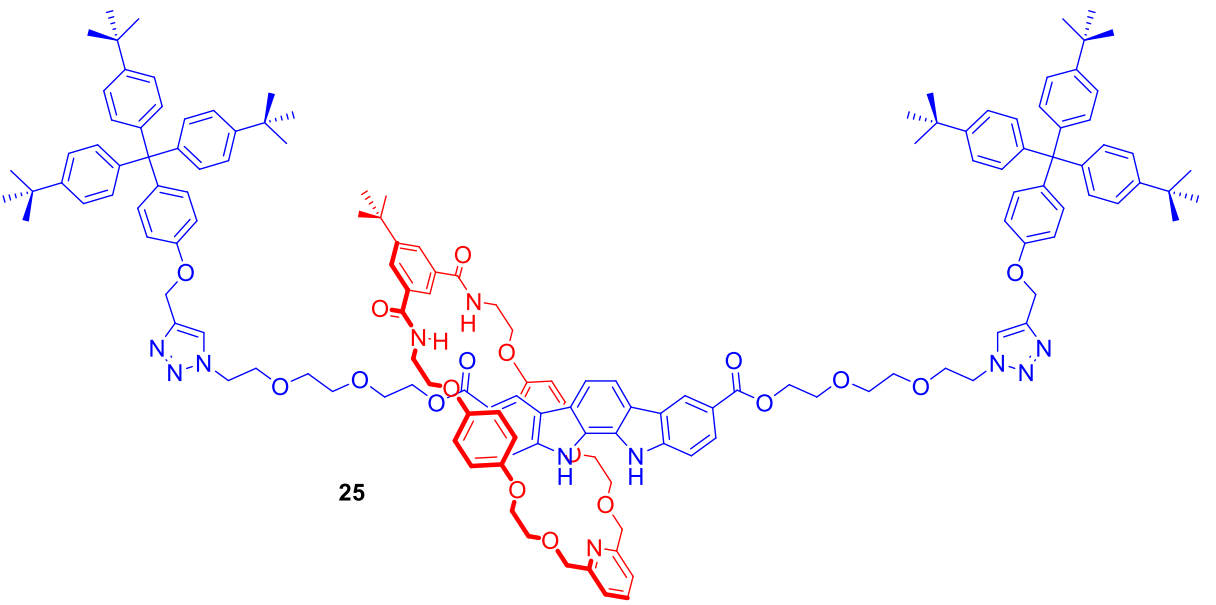

Figure 14 Fluorescent [2] rotaxanes obtained via AMT-CuAAC strategy.

naphthalimide group in the axle component (Fig. 14). ${ }^{56}$ Strong intramolecular hydrogen bonds between the urea and bipyridyl moiety of the macrocycle prevented anion binding. However, protonation of the bipyridyl unit translocated the macrocycle facilitating binding of anions to the urea. $\ln \mathrm{CDCl}_{3} / \mathrm{CD}_{3} \mathrm{CN} 1: 1$ the determined anion association constant values of $\mathbf{2 4} \cdot \mathrm{H}^{+}$followed the trend: $\mathrm{Cl}^{-}>\mathrm{Br}^{-}>\mathrm{MsO}^{-}>\mathrm{HSO}_{4}^{-}>\mathrm{TsO}^{-}>\mathrm{I}^{-}$which reflects a combination of the $\mathrm{H}$-bond accepting properties of anions ${ }^{57}$ and size preference of the rotaxane. The binding event was accompanied by a switch-on fluorescence response of the axle naphthalimide group.

AMT was also used to synthesise neutral [2]rotaxane 25 containing a fluorescent indolocarbazole-based axle component and an isophthalamide functionalised macrocycle (Fig. 14). ${ }^{58}$ Binding studies in $\left(\mathrm{CD}_{3}\right)_{2} \mathrm{CO} / \mathrm{D}_{2} \mathrm{O} 95: 5$ revealed this MIM host system to exhibit a preference for AcO- and $\mathrm{H}_{2} \mathrm{PO}_{4}^{-}$ binding over halides. The rotaxane's axle indolocarbazole moiety facilitated the selective fluorescent sensing of chloride by significant enhancement of the heterocycle fluorophore's emission, whilst addition of other anions such as $\mathrm{H}_{2} \mathrm{PO}_{4}^{-}, \mathrm{AcO}^{-}$or $\mathrm{F}$-led to substantial quenching.

Another approach allowed Byrne, Gunnlaugsson and coworkers to obtain an anion binding [2]catenane via selfcomplementary hydrogen bond formation. ${ }^{59}$ In this case RCM was exploited to perform a double cyclisation to produce a homo catenane $\mathbf{2 6}$ (Fig. 15)which was shown to selectively bind $\mathrm{H}_{2} \mathrm{PO}_{4}^{-}$over $\mathrm{Cl}^{-}, \mathrm{SO}_{4}^{2-}$ or $\mathrm{NO}_{3}^{-}$in competitive solvents like $\mathrm{d}_{6}$-DMSO.

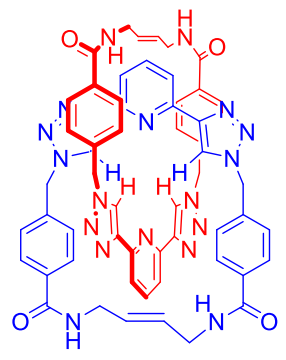

26

Figure 15 Anion binding MIM obtained via self-complementary hydrogen bond formation.
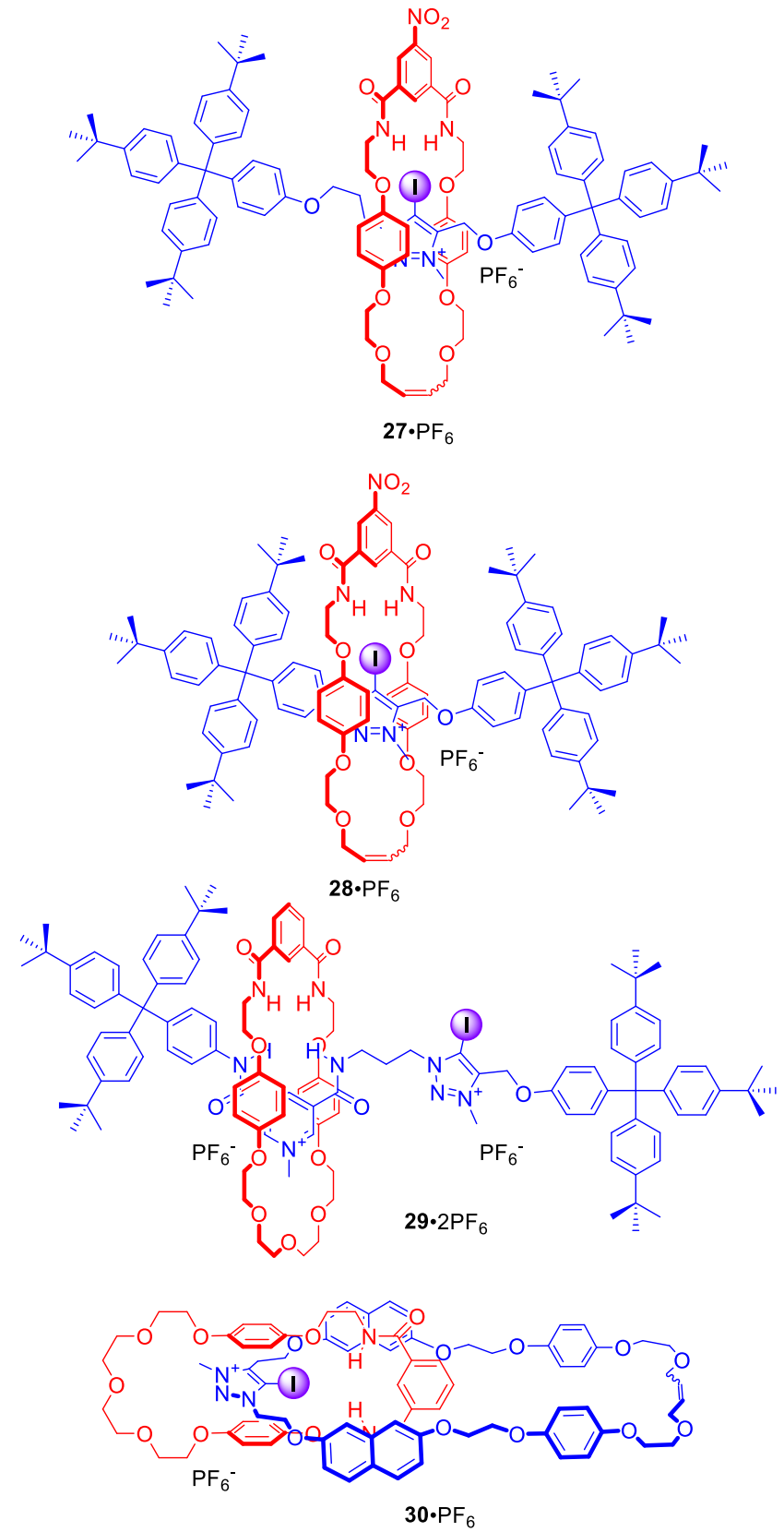

Figure 16 Anion binding MIMs incorporating iodotriazoloum motif. 


\section{$H B / X B$ MIM host systems}

Since the first example of a halogen bonding rotaxane 27. $\mathrm{PF}_{6}$ (Fig. 16), ${ }^{60}$ the iodotriazolium motif has been widely exploited in our group to construct MIMs with enhanced binding and sensing properties. For example, shortening of the axle component in rotaxane $28 \cdot \mathrm{PF}_{6}$ resulted in a higher degree of preorganisation leading to a significant increase of halide binding strength and enhanced selectivity for iodide in the competitive solvent mixture $\mathrm{CDCl}_{3} / \mathrm{CD}_{3} \mathrm{OD} / \mathrm{D}_{2} \mathrm{O} 45: 45: 10 .{ }^{61}$ The iodotriazolium motif was also used to improve halide recognition, in particular of bromide and iodide, in the binding cavity of rotaxane $29 \cdot 2 \mathrm{PF}_{6}$ in concert with amide $\mathrm{HB}$ donors. ${ }^{62}$

[2] Catenane 30. $\mathrm{PF}_{6}$ consisted of the iodotriazolium based macrocycle containing naphthalene groups in close proximity to the binding pocket (Fig. 16). ${ }^{63}$ Addition of various anions, particularly acetate and dihydrogen phosphate, to a solution of 30. $\mathrm{PF}_{6}$ in acetonitrile caused an increase of the naphthalene monomer emission bands and the concomitant decrease in intensity of an excimer emission band. The observed sensory response was attributed to the increased rigidity reducing the number of available vibrational and rotational non-radiative decay pathways upon anion binding.

In 2014 we demonstrated for the first time $X B$ anion recognition in water and showed that incorporating $X B$ donors into a rotaxane structure results in a significant enhancement of anion binding strength and selectivity in water compared to hydrogen bond analogues. ${ }^{64}$ [2]Rotaxanes $31 \cdot 2 \mathrm{NO}_{3}$ and $32 \cdot 2 \mathrm{NO}_{3}$ consisted of a hydrogen bond donating bis-amide pyridinium macrocycle and the axle component stoppered on both sides with permethylated $\beta$-cyclodextrins, which imparted solubility in water (Fig. 17). The binding constant of $\mathrm{I}^{-}$in water by bis-iodotriazole rotaxane $\mathbf{3 1} \mathbf{b} \cdot 2 \mathrm{NO}_{3}$ was two orders of magnitude larger than that of the rotaxanes $31 \mathrm{a} \cdot 2 \mathrm{NO}_{3}$ and $32.2 \mathrm{NO}_{3}$ containing bis-triazole or bis-amide motifs in their axles. Thermodynamic binding data showed that the large
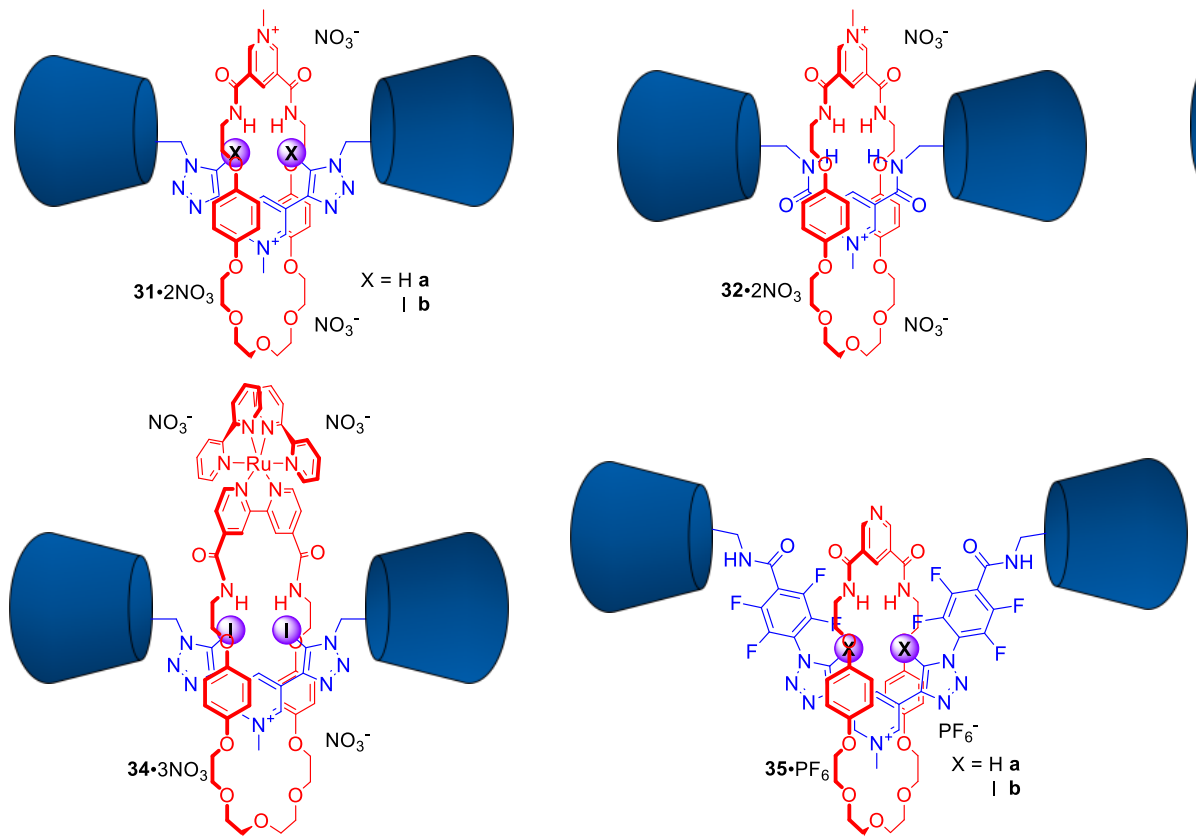
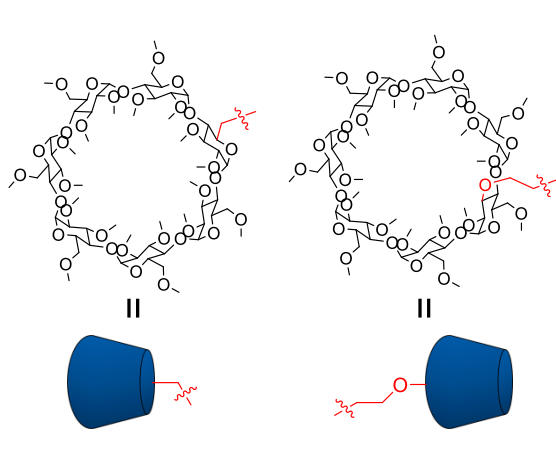

association constant for $\mathrm{I}^{-}$with iodotriazole rotaxane $\mathbf{3 1 \mathbf { b }} \cdot 2 \mathrm{NO}_{3}$ was the sole result of favourable enthalpy manifesting extraordinary properties of $\mathrm{XB}$ in water. In contrast iodide binding of both rotaxanes $31 \mathrm{a} \cdot 2 \mathrm{NO}_{3}$ and $32 \cdot 2 \mathrm{NO}_{3}$ was entropically driven and enthalpically disfavoured. Further studies of the hydrogen bonding analogue $33 \cdot 2 \mathrm{NO}_{3}$ containing a wider, secondary rim functionalised cyclodextrin stoppers showed no significant difference in anion binding comparing to 32. $2 \mathrm{NO}_{3} .{ }^{65}$ This observation suggested that the influence of the bulky cyclodextrin derivatives on a MIM binding cavity was negligible.

The excellent binding properties of $\mathbf{3 1} \mathbf{b} \cdot 2 \mathrm{NO}_{3}$ in aqueous media became the basis for the development of the first MIM host system capable of the selective sensing of iodide in water. The integration of a bipyridyl motif into the macrocyclic component led to rotaxane $\mathbf{3 4} \cdot \mathbf{3} \mathrm{NO}_{3}$ containing the photoactive $\left[\mathrm{Ru}(\text { bipy })_{2}\right]^{2+}$ group (Fig. 17). ${ }^{66}$ It exhibited a further increase in anion binding strength and facilitated the luminescent sensing of iodide in water via an enhancement of metal-to-ligand charge transfer (MLCT) emission intensity upon anion recognition. Further structural elaboration of rotaxane $31 \cdot 2 \mathrm{NO}_{3}$ included the insertion of electron withdrawing perfluoroaryl spacers between the iodotriazole motif and cyclodextrin stoppers, which sought to further increase the strength of XBanion interactions. ${ }^{67}$ This modification allowed for the synthesis of rotaxane $\mathbf{3 5 b} \cdot \mathrm{PF}_{6}$ (Fig. 17) via chloride templated amide condensation in an unprecedented near quantitative $91 \%$ yield. Monocationic 35b $\cdot \mathrm{PF}_{6}$ was able to bind iodide with an association constant of $>10^{5} \mathrm{M}^{-1}$ in $\mathrm{D}_{2} \mathrm{O} /\left(\mathrm{CD}_{3}\right)_{2} \mathrm{CO} 1: 1$, which was at least three orders of magnitude greater in comparison to a hydrogen bonding rotaxane host analogue $35 \mathrm{a} \cdot \mathrm{PF}_{6}$.

The above examples demonstrated the potency of the bisiodotriazole pyridinium moiety working in concert with hydrogen bond donors in rotaxane structures. Similar binding motifs were also incorporated into the structure of [2] catenane 36. $\mathrm{PF}_{6}$ (Fig. 18), which was able to selectively bind $\mathrm{I}^{-}$and $\mathrm{Br}^{-}$over

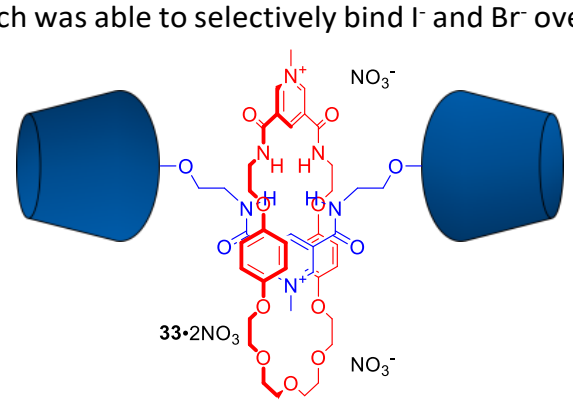

Figure 17 Anion binding MIMs containing permethylated $\beta$-cyclodextrin stoppers. 
a)

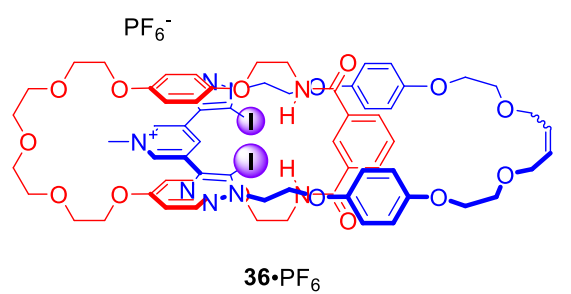

b)

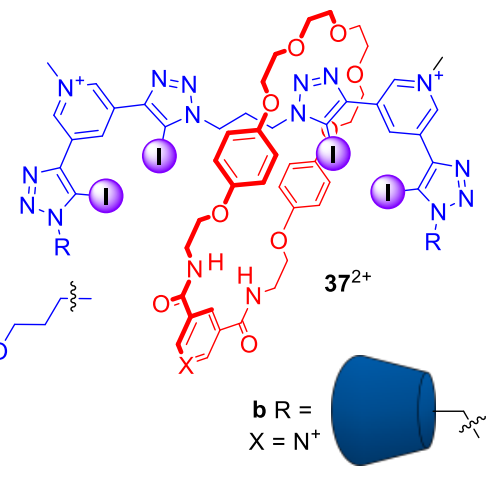

Figure 18 (a) Anion binding [2]catenane containing bis-iodotriazole pyridinium motif. (b) Anion binding [2]rotaxanes containing two bis-iodotriazole pyridinium motifs in the axle.

$\mathrm{Cl}^{-} .{ }^{68}$ Moreover, various oxoanions showed no affinity towards 36. $\mathrm{PF}_{6}$ in solution and its crystal structure grown in the presence of $\mathrm{SO}_{4}{ }^{2-}$ revealed that sulfate was too large to be accommodated by the interlocked binding cavity. Importantly, analysis of halide complexes of catenane $\mathbf{3 6}$ by X-ray Absorption Spectroscopy (XAS) provided for the first time a direct measure of the degree of covalency in the XB-anion interaction. It was found to be comparable to the degree of covalency in transition metal complexes of chloride.

Further work on the interlocked anion receptors containing bis-iodotriazole pyridinium motif involved covalently linking two of these moieties in the axle of rotaxanes $37 \mathrm{a} \cdot 2 \mathrm{PF}_{6}$ and 37b.30Tf (Fig. 18). ${ }^{69}$ Receptor 37a.2PF 6 was able to bind chloride with significantly higher affinity than nitrate in $\mathrm{CDCl}_{3} / \mathrm{CD}_{3} \mathrm{OD} / \mathrm{D}_{2} \mathrm{O} 45: 45: 10$. On the other hand $\beta$-cyclodextrin stoppered rotaxane $\mathbf{3 7 b} \cdot \mathbf{3 0 T f}$ displayed almost identical association constants with $\mathrm{Cl}^{-}$and $\mathrm{NO}_{3}{ }^{-}$in $\mathrm{D}_{2} \mathrm{O} /\left(\mathrm{CD}_{3}\right)_{2} \mathrm{CO}$ 9:1 proving once again the outstanding potential of halogen bonding in aqueous solutions.

A chiral $\mathrm{XB}$ [3] rotaxane $38 \cdot 2 \mathrm{PF}_{6}$ consisting of two mechanically bonded $\mathrm{HB}$ macrocycles and an axle component with two bis-iodotriazole pyridinium moieties linked by a fluorescent (S)-BINOL group (Fig. 19) enabled discrimination between dicarboxylic enantiomers (R) vs. (S)-N-Boc-Glu²- and between geometric isomers malonate vs. fumarate. These dicarboxylate anion guest species were simultaneously bound by the extended cavity of [3] rotaxane in a sandwich type complex. ${ }^{70}$ Computational modelling investigations suggested that the impressive geometric isomer selectivity of $38.2 \mathrm{PF}_{6}$ for fumarate $\left(\mathrm{K}_{\text {fumarate }} / \mathrm{K}_{\text {malonate }}=4.4\right.$ ) in $\mathrm{CHCl}_{3} / \mathrm{CH}_{3} \mathrm{OH} / \mathrm{H}_{2} \mathrm{O}$ 60:39:1 was mainly attributed to anion solvation effects inside the binding cavity. In contrast, the notably high enantioselectivity of $38 \cdot 2 \mathrm{PF}_{6}$ for $(\mathrm{S})-\mathrm{N}-\mathrm{Boc}_{-} \mathrm{Glu}^{2-}$ arose primarily from host-guest

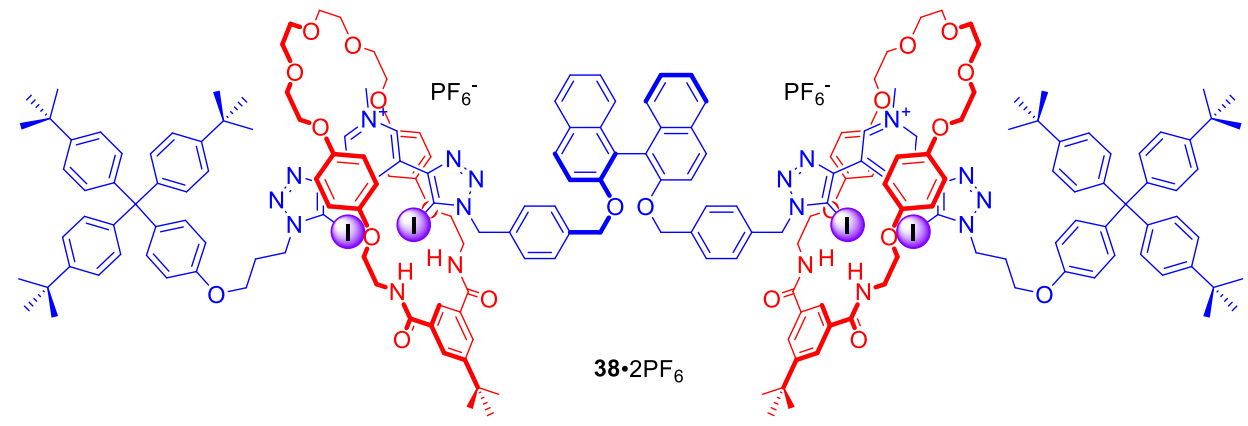

Figure 19 Chiral [3]catenane capable of enantioselective anion sensing.

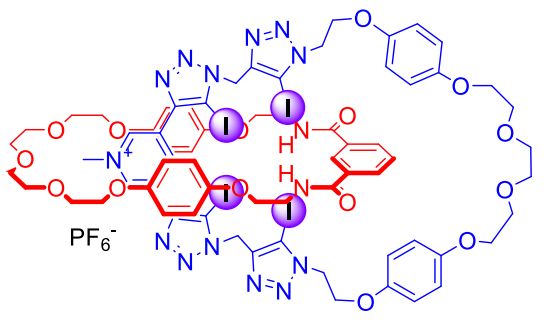

$39 \cdot \mathrm{PF}_{6}$

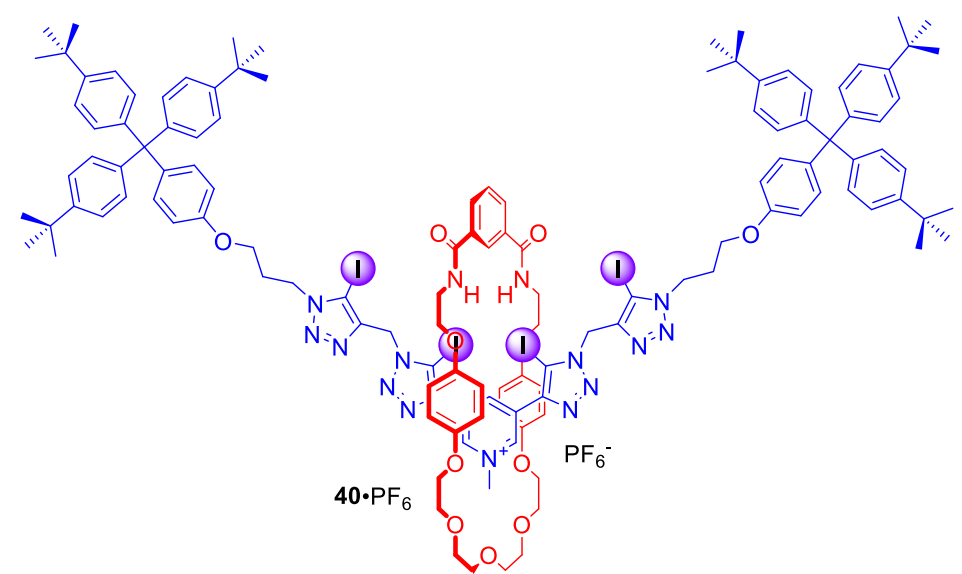

Figure 20 Anion binding MIMs containing tetra(iodotriazole)-pyridinium group. 


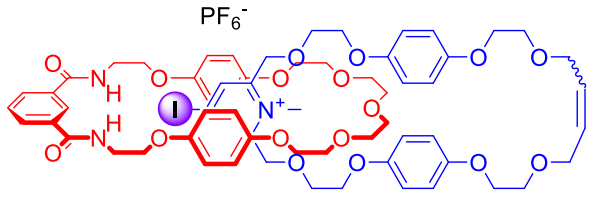

$41 \cdot P F_{6}$

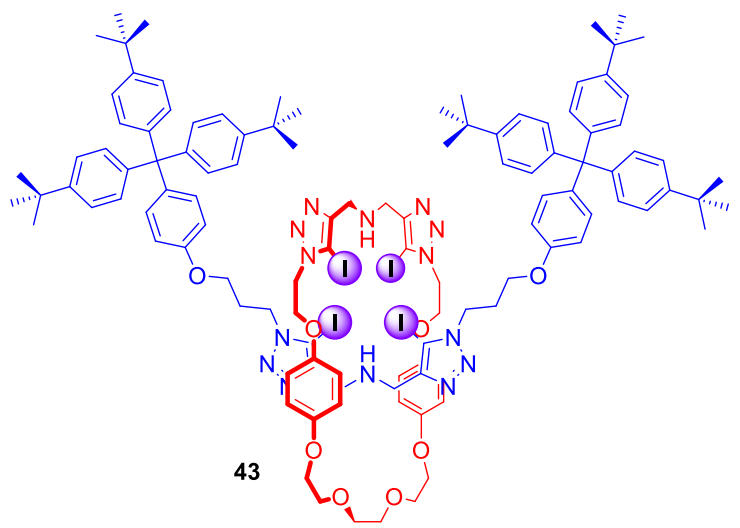

Figure 21 Anion binding MIMs containing XB and HB donors.

structural complementarity $\left(K_{S} / K_{R}=5.7\right)$. Moreover, the binding of dicarboxylates could be readily sensed by fluorescence quenching of rotaxane's axle BINOL fluorophore emission.

Recently, a novel XB tetra(iodotriazole)-pyridinium group was incorporated into MIM structures of catenane $39 \cdot \mathrm{PF}_{6}$ and rotaxane 40. $\mathrm{PF}_{6}$ (Fig. 20). ${ }^{71}$ Interestingly, significant differences in anion binding strengths were observed for these MIMs. Although both $\mathbf{3 9}$ and $\mathbf{4 0}$ are monocationic, rotaxane $\mathbf{4 0} \cdot \mathrm{PF}_{6}$ bound iodide almost three times stronger than catenane 39. $\mathrm{PF}_{6}$ in $\mathrm{CDCl}_{3} / \mathrm{CD}_{3} \mathrm{OD} / \mathrm{D}_{2} \mathrm{O}$ 45:45:10. Moreover, catenane 39. $\mathrm{PF}_{6}$ bound iodide even more weakly than its analogue 36. $\mathrm{PF}_{6}$ with only two halogen bond donors. This difference might be a result of steric constraints restricting access to the binding cavity.

Other motifs used in the construction of mixed halogen and hydrogen bond donating interlocked anion receptors included 4-bromo(iodo)pyridinium in [2]catenane $41 \cdot \mathrm{PF}_{6},{ }^{72}$ bisiodotriazolium carbazole in [2] rotaxane $42 \cdot 2 \mathrm{PF}_{6},{ }^{73}$ and bisiodotriazole amine in electroneutral [2] rotaxanes $\mathbf{4 3}$ and $\mathbf{4 4}$ (Fig. 21). ${ }^{74}$ The last of these are particularly interesting since conformational flexibility of combined Lewis basic and Lewis acidic groups facilitates rotaxanes $\mathbf{4 3}$ and $\mathbf{4 4}$ to strongly bind transition metal cations via bis-tridentate $\mathrm{N}$-donor coordination and to bind anions weakly through $\mathrm{XB}$ and $\mathrm{HB}$ interactions. Protonation of the central amine moiety, however, reverses binding properties allowing for much stronger anion binding and negating metal cation recognition.

In a similar manner to using electron-deficient heavy halogen atoms for XB anion recognition, electron-deficient heavy chalcogen atoms can be exploited to bind anions via favourable chalcogen bonding (ChB) interactions. The first

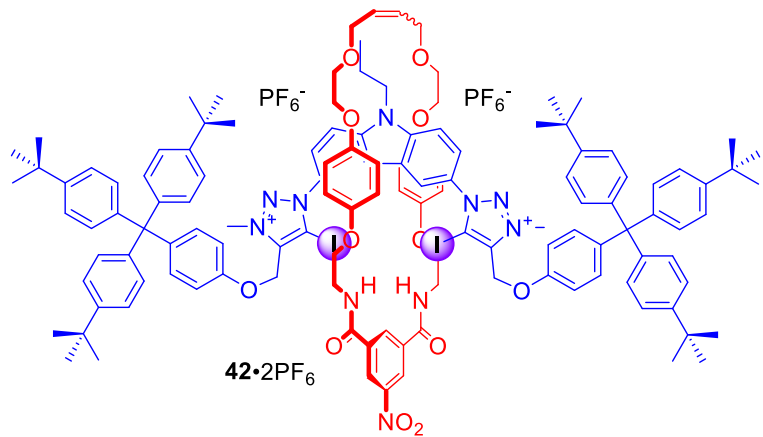

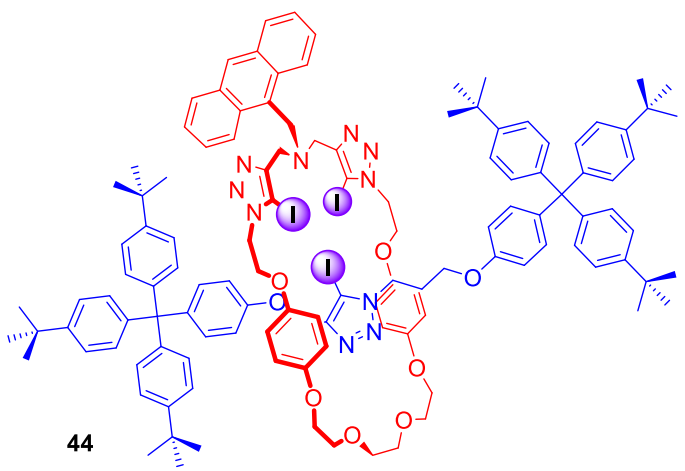

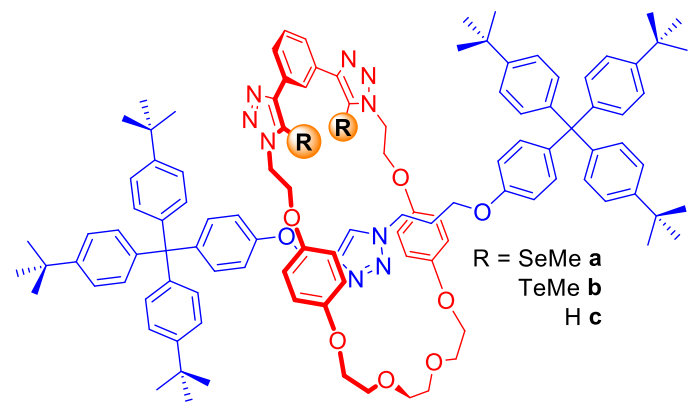

45

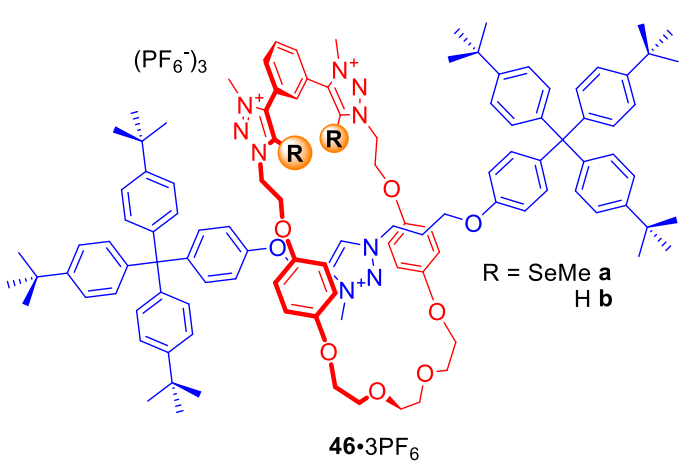

Figure 22 Chalcogen bonding [2] rotaxanes.

examples of chalcogen bonding MIMs were [2]rotaxanes 45a-b and $46 \mathrm{a} \cdot 3 \mathrm{PF}_{6}$ (Fig. 22) synthesised by AMT CuACC reaction, in which $\mathrm{Cu}(\mathrm{I})$ was coordinated via the chalcogen atoms themselves. ${ }^{75}$ Anion binding studies in $\mathrm{d}_{6}$-acetone revealed that electroneutral rotaxane $\mathbf{4 5 b}$ containing Te atoms is a more potent MIM host in comparison to the hydrogen bonding and Se analogues 45c and 45a. A comparison of anion binding properties of triply charged rotaxanes $46 \mathrm{a} \cdot 3 \mathrm{PF}_{6}$ and $46 \mathrm{~b} \cdot 3 \mathrm{PF}_{6}$ in $\left(\mathrm{CD}_{3}\right)_{2} \mathrm{CO} / \mathrm{D}_{2} \mathrm{O} 4: 1$ also showed significant differences. For 


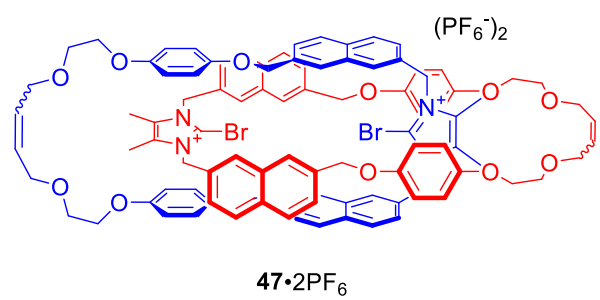

Figure 23 First all XB examples of catenane and rotaxane.

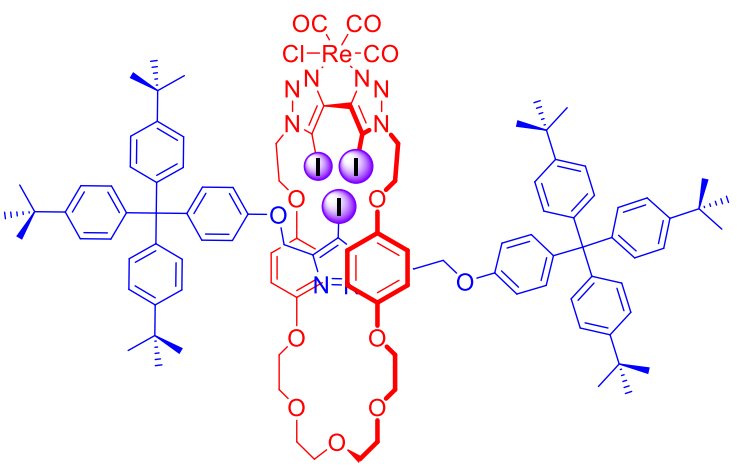

49

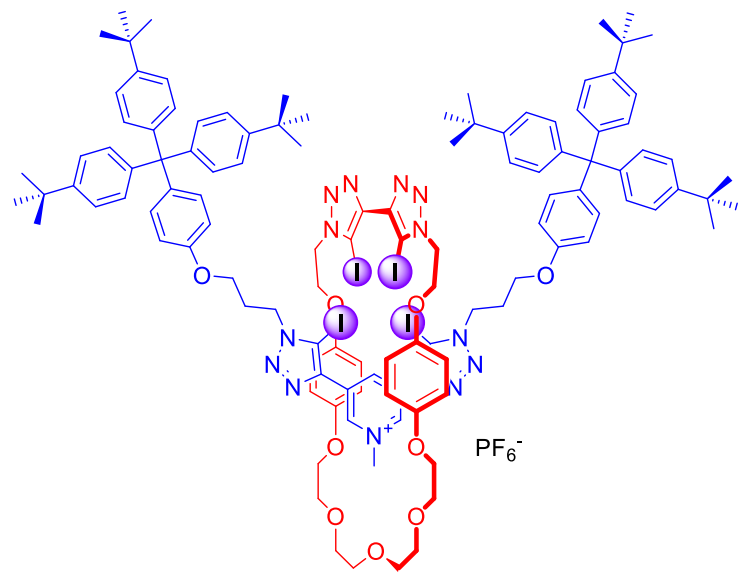

$\mathbf{5 1} \cdot \mathrm{PF}_{6}$

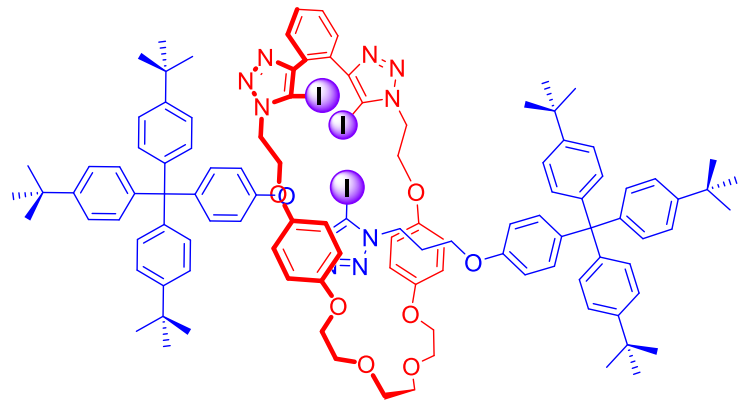

53

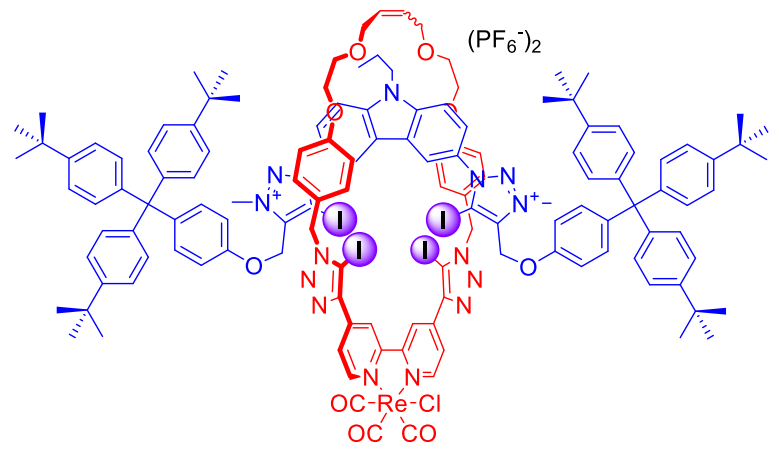

48. $2 \mathrm{PF}_{6}$

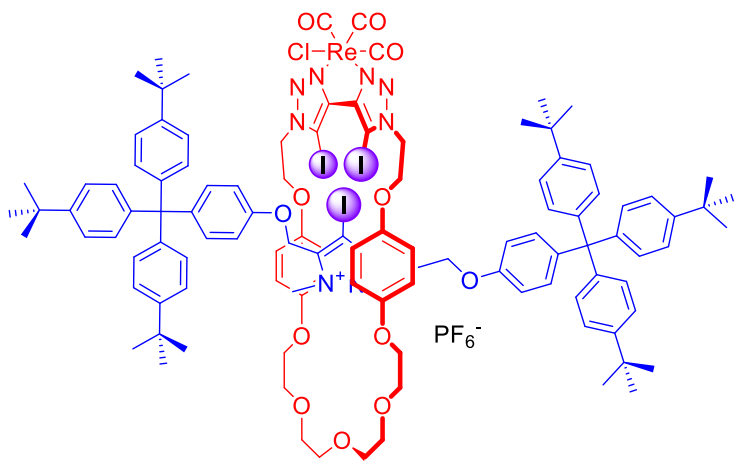

50. $\mathrm{PF}_{6}$
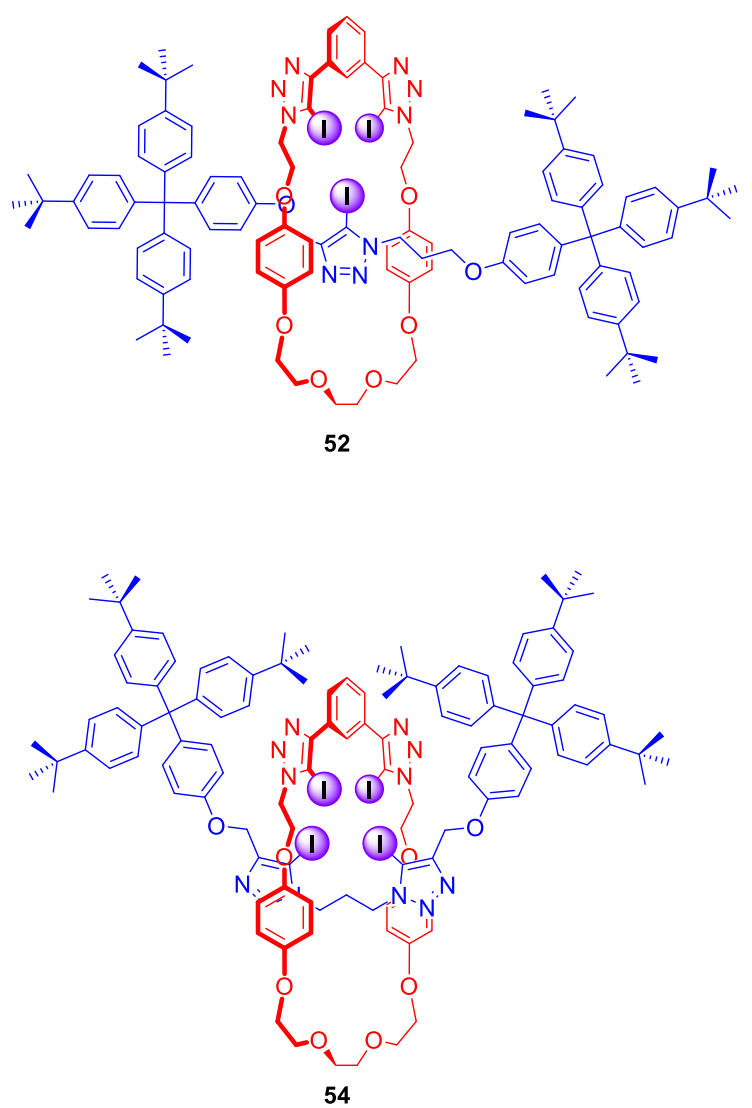
instance, the chalcogen rotaxane bound halides with affinities decreasing in the order $\mathrm{I}^{-}>\mathrm{Br}^{-}>\mathrm{Cl}^{-}$, while $46 \mathrm{~b} \cdot 3 \mathrm{PF}_{6}$ showed significant selectivity for $\mathrm{Br}^{-}$. The biggest difference was observed for acetate binding with an enhancement in association constant over 2 orders of magnitude larger for the $\mathrm{HB}$ host $\mathbf{4 6 b} \cdot 3 \mathrm{PF}_{6}$.

\section{All XB MIM host systems}

The first halogen bonding MIM which did not contain strong hydrogen bond donors (like amide $\mathrm{NH}$ ) was [2] catenane $47 \cdot 2 \mathrm{PF}_{6}$ (Fig. 23) prepared by bromide anion templation. ${ }^{76}$ The first allhalogen bonding rotaxane was [2] rotaxane $48 \cdot 2 \mathrm{PF}_{6}$ (Fig. 23) obtained by chloride templation. ${ }^{77}$ Its axle component was based on a bis-(iodo)triazolium carbazole moiety while the macrocycle contained a photoactive rhenium (I) bipyridyl entity. Quenching of its MLCT emission band allowed for selective fluorescent sensing of halides, in particular $\mathrm{I}^{-}$, over a range of oxoanions in aqueous solvent mixtures containing up to $50 \%$ water.

The CUACC-AMT strategy has proved to be particularly useful in the preparation of anion binding interlocked hosts containing iodotriazole motifs as halogen bond donors. The first example of such a structure was [2] rotaxane $\mathbf{4 9}$ (Fig. 24), whose macrocyclic component contained a bis-iodotriazole group capable of forming an endotopic complex with $\mathrm{Cu}(\mathrm{I}) .{ }^{78}$ Removal of the copper template and subsequent metalation with a more sterically demanding rhenium(I) complex inverted the geometry of the macrocycle, forcing the transition metal to adopt an exotopic orientation and directing XB-donors into the rotaxane's cavity. Although rotaxane $\mathbf{4 9}$ was not luminescent, a decrease in the MLCT absorption band could be observed upon addition of anions in $\mathrm{CHCl}_{3}$. Association constants of this electrically neutral rotaxane with anions followed the trend $\mathrm{Cl}^{-}$ $>\mathrm{Br}^{-}>\mathrm{I}^{-}>\mathrm{AcO}^{-}$. The positively charged analogue 50. $\mathrm{PF}_{6}$ was shown to exclusively bind bromide over chloride, iodide and oxoanions in $\left(C_{3}\right)_{2} \mathrm{CO} / \mathrm{D}_{2} \mathrm{O}$ 9:1, whereas the corresponding metal-free rotaxane 51. $\mathrm{PF}_{6}$ displayed Hofmeister bias halide selectivity: $\mathrm{I}^{-}>\mathrm{Br}^{-}>\mathrm{Cl}^{-} .{ }^{79}$

The AMT strategy was also employed in the synthesis of a variety of neutral XB rotaxanes 52-54 (Fig. 24) with increasing number of XB donors inside the binding cavity. ${ }^{80}$ Rotaxanes 52

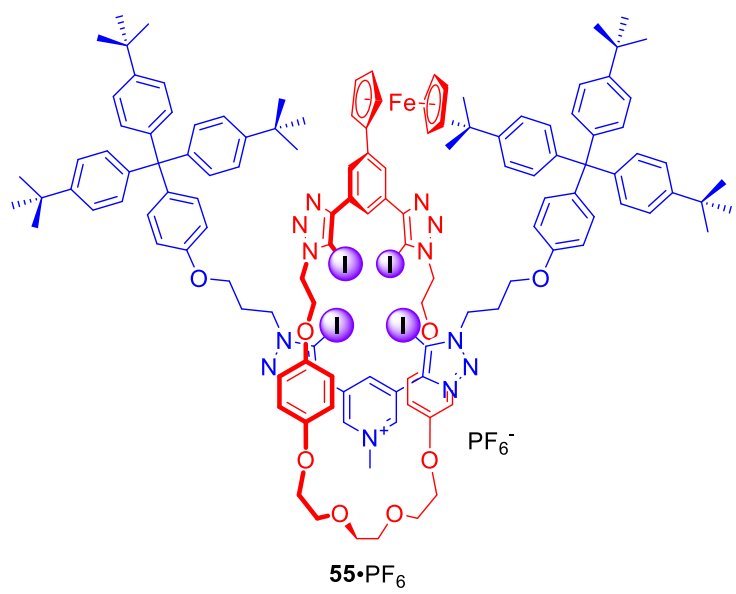

Figure 25 Electrochemically active XB [2]rotaxane and 53 bound anions in $d_{6}$-acetone following the selectivity trend of $\mathrm{SO}_{4}{ }^{2-}>\mathrm{Cl}^{-}>\mathrm{Br}^{-}>\mathrm{I}^{-}$, which corresponds to a decreasing charge density and basicity of the guest anion. Rotaxane $\mathbf{5 2}$ bound anions much more strongly than $\mathbf{5 3}$ by up to two orders of magnitude, demonstrating the importance of the spatial separation of iodotriazole groups in the receptors. Interestingly, in a $\left(C_{3}\right)_{2} C O / D_{2} \mathrm{O} 98: 2$ solvent mixture the reverse anion binding selectivity was observed: $\mathrm{I}^{-}>\mathrm{Br}^{-}>\mathrm{Cl}^{-}>\mathrm{SO}_{4}{ }^{2-}$. In the case of $\mathbf{5 4}$ binding of bromide was stronger than that of iodide. However, this preference disappeared upon increasing water
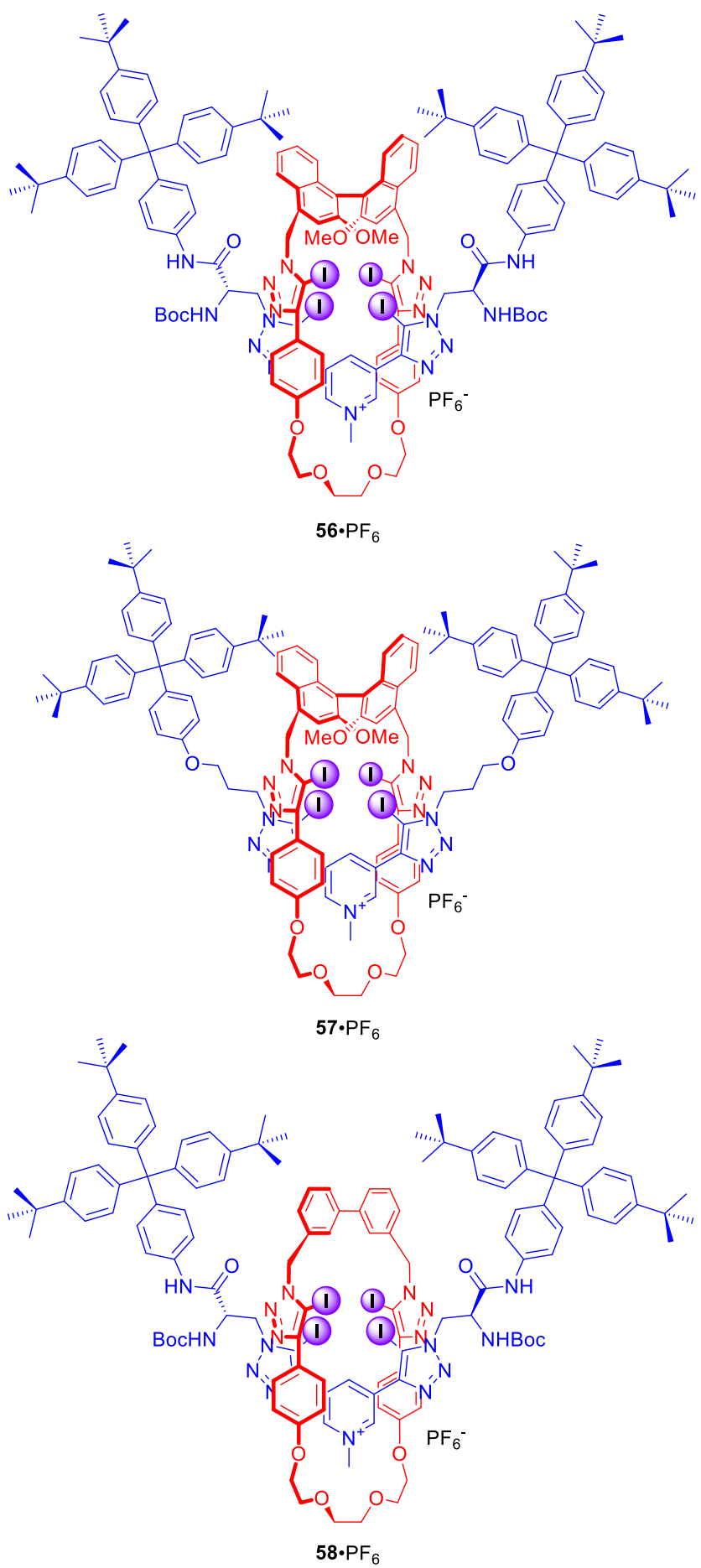

Figure 26 Chiral XB [3]rotaxanes. 
content to $5 \%$, underscoring the importance of anion hydration in the binding process.

A redox-active ferrocene appended [2] rotaxane 55. $\mathrm{PF}_{6}$ containing four halogen bond donors in its cavity was also obtained via the AMT-CuAAC strategy (Fig. 25). ${ }^{81}$ Anion binding studies in $\mathrm{CD}_{3} \mathrm{CN} /\left(\mathrm{CD}_{3}\right)_{2} \mathrm{CO} / \mathrm{D}_{2} \mathrm{O}$ 45:45:10 revealed that rotaxane 55 displayed Hofmeister anion binding preference: $\left.\right|^{-}>$ $\mathrm{Br}^{-}>\mathrm{Cl}^{-}>\mathrm{SO}_{4}{ }^{2-}$. This trend was also reflected in the electrochemical sensing behaviour of $\mathbf{5 5} \cdot \mathrm{PF}_{6}$ where a larger magnitude of cathodic perturbation of the ferrocene/ferrocenium redox couple for $\mathrm{Br}^{-}$over $\mathrm{Cl}^{-}$in the presence of water was demonstrated.

Four halogen bond donors were also present in the structure of [2]rotaxanes 56-58. $\mathrm{PF}_{6}$ (Fig. 26). ${ }^{82}$ The macrocyclic component of 56-58.PF $\mathrm{P}_{6}$ contained two iodotriazole motifs separated by either (S)-BINOL (56. $\mathrm{PF}_{6}$ and 57.PF $)$ or an achiral biphenyl group (58. $\mathrm{PF}_{6}$ ). The axle component incorporated a bis-iodotriazole pyridinium moiety stoppered by a chiral serine

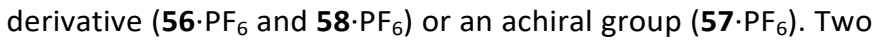
chiral components in rotaxane 56. $\mathrm{PF}_{6}$ formed a unique binding pocket which allowed for significant enantioselectivity in binding of N-Boc amino acid derivatives: Leu, Pro, Trp and $\mathrm{BINOLPO}_{4}$ in $\left(\mathrm{CD}_{3}\right)_{2} \mathrm{CO} / \mathrm{D}_{2} \mathrm{O}$ 98:2. Rotaxane 56.PF $\mathrm{F}_{6}$ showed selectivity for the S-enantiomer of amino acids and the $\mathrm{R}$ enantiomer of BINOL-phosphate. Surprisingly, 57.PF 6 (chiral macrocycle and achiral axle) exhibited the reverse selectivity for $\mathrm{R}$ amino acids, whilst 58. $\mathrm{PF}_{6}$ (achiral macrocycle and chiral axle) showed practically no enantioselectivity. This suggested that the chiral XB macrocycle component of rotaxane exerted a dominating influence on the effectiveness of chiral discrimination, which may be partly due to the greater rigidity and larger steric bulk of the macrocycle's chiral (S)-BINOL group as compared to the point-chiral (S)-serine-derived asymmetric units of the axle.

\section{Dynamic MIM systems for anion recognition and sensing}

In the above examples anion binding by MIMs in general was achieved via anion guest encapsulation within their unique three dimensional preorganized binding cavities. Any conformational changes experienced by these molecules upon a binding event were relatively minor and limited mostly to rigidifying the interlocked structure. Dynamic MIMs designed to undergo large amplitude changes of their co-conformation triggered by anion recognition are discussed as a separate category in this section.

Halogen bonding MIMs in most cases exhibit a strong preference for iodide binding over chloride in competitive protic solvent mixtures. Our group prepared rotaxane $59 \cdot 2 \mathrm{PF}_{6}$ (Scheme 2), whose axle component contained XBiodotriazolium and $\mathrm{HB}$-triazolium stations separated by a naphthalene moiety. ${ }^{83}$ The contrasting halide anion binding affinities of these stations allowed shuttling of the macrocyclic component along the axle (Scheme 2). In the presence of $\mathrm{Cl}^{-}$, the macrocycle displayed $100 \%$ occupancy of the HB-triazolium station in $\mathrm{CDCl}_{3} / \mathrm{CD}_{3} \mathrm{OD} 1: 1$. The high affinity of iodide to $\mathrm{XB}$ iodotriazolium caused shuttling of the macrocycle in response

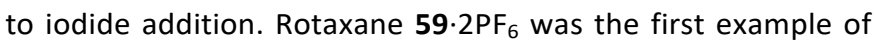
using $X B$ in the solution phase to control MIM molecular motion.

[2]Rotaxanes $\mathbf{6 0 a} \cdot \mathrm{PF}_{6}$ and $\mathbf{6 0 b} \cdot \mathrm{PF}_{6}$ were examples of dynamic anion binding MIMs capable of sensing (Scheme 3). ${ }^{84}$ The axle component of these systems contained an electron deficient naphthalene diimide (NDI) motif exhibiting aromatic donor-acceptor charge transfer interactions with the electron

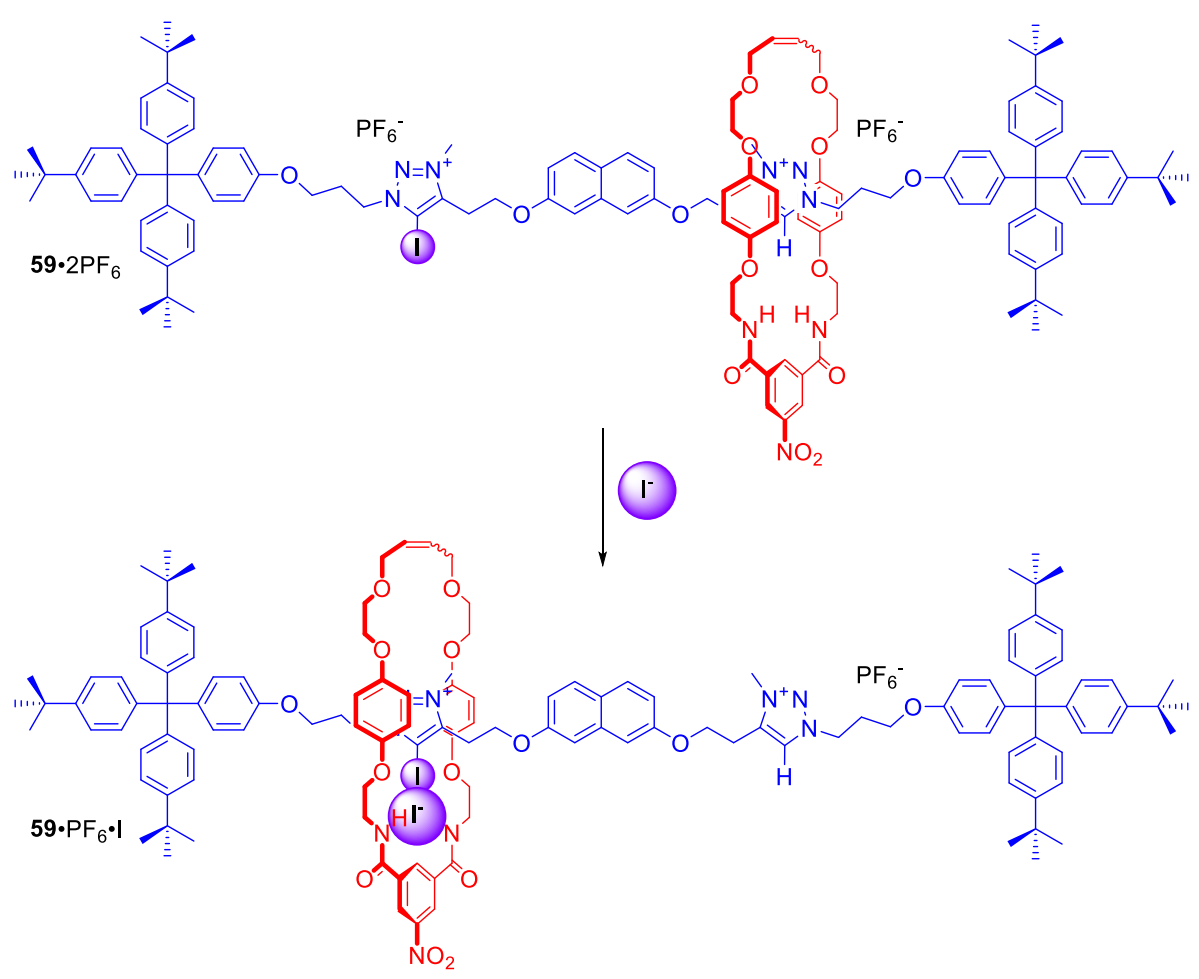




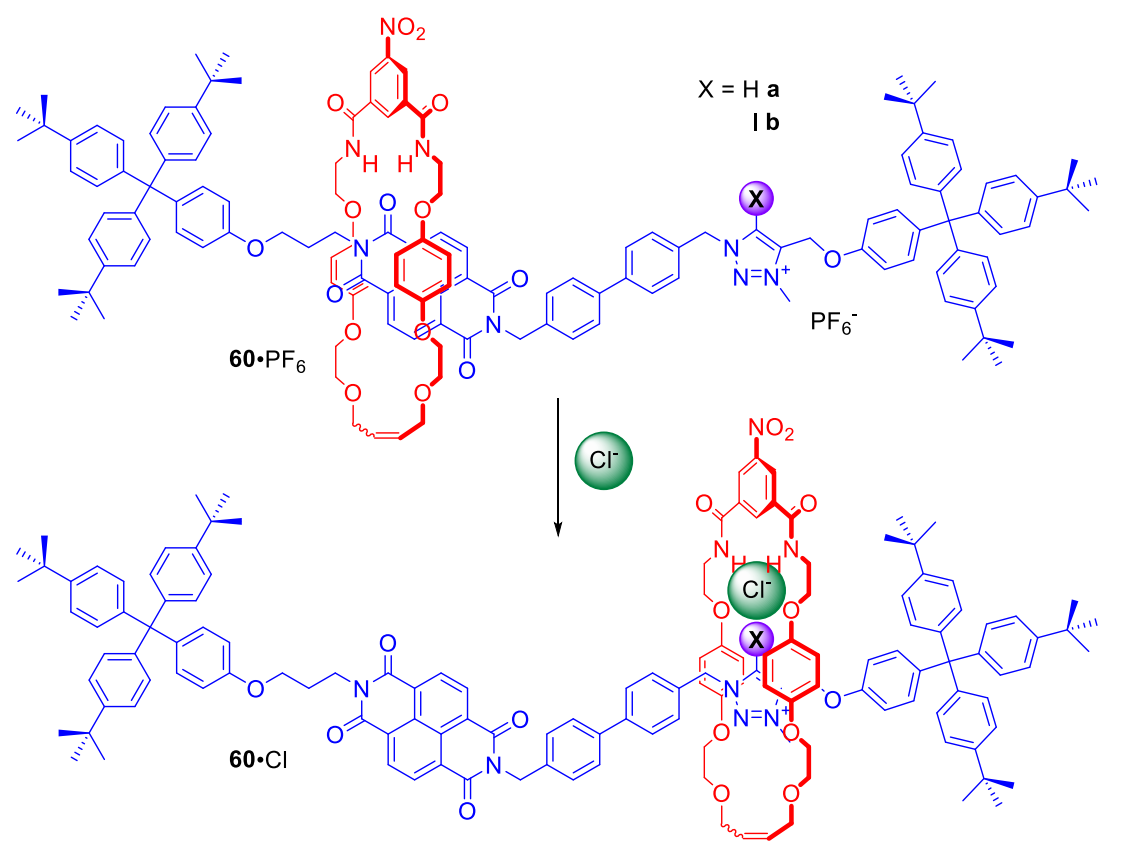

Scheme 3 Chloride-driven shuttling of [2]rotaxane.
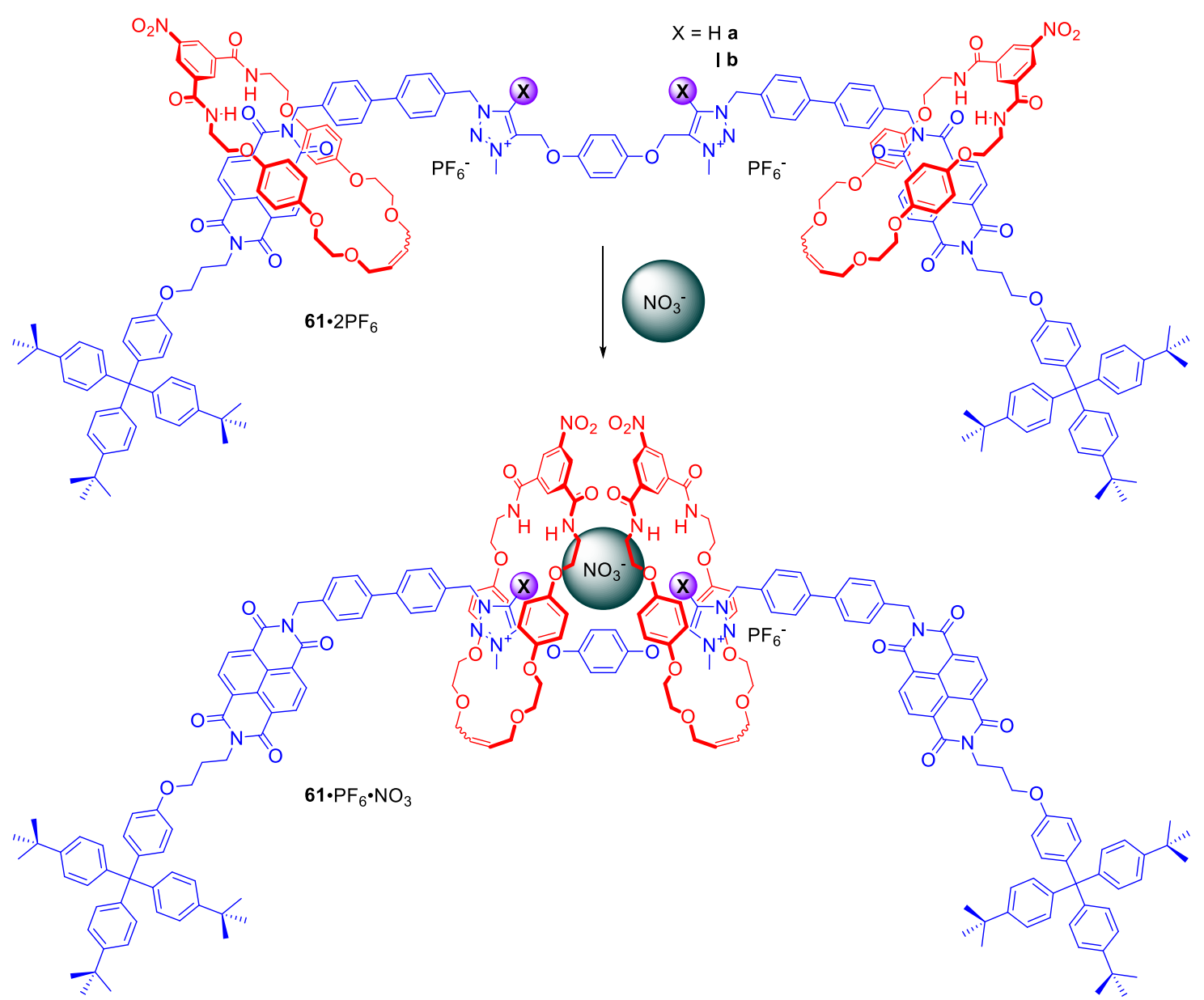

Scheme 4 Nitrate-driven shuttling of [3]rotaxane. 


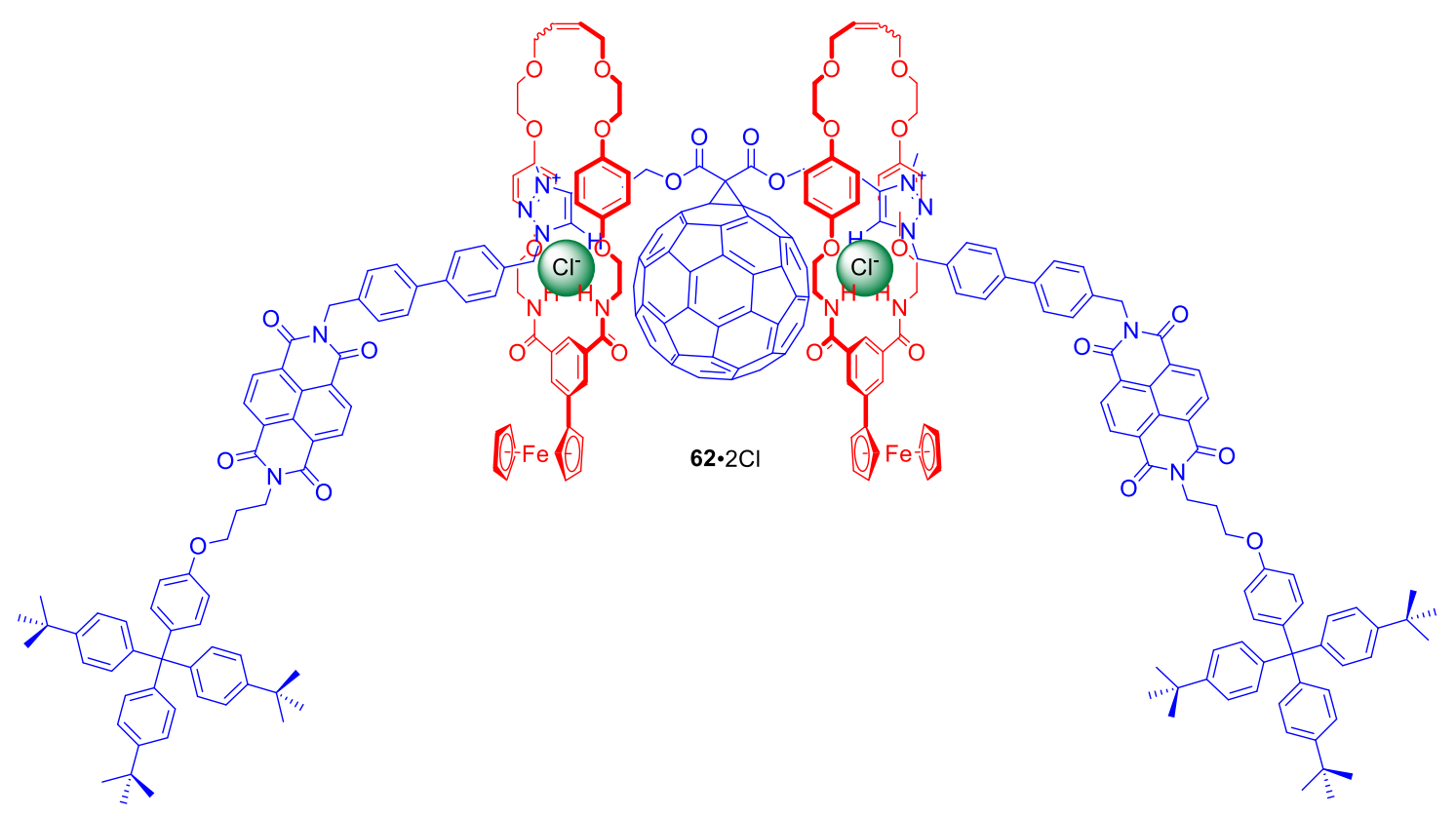

Figure 27 Chloride complex of [3] rotaxane incorporating fullerene in the axle component.

rich hydroquinone groups of the macrocycle component. The second station on the axle was a positively charged XB iodo- or HB proto-triazolium group which could participate in anion binding. In the presence of chloride, the macrocyclic component resided over the axle's triazolium station as a result of anion coordination to both rotaxane's components. Exchange of chloride to hexafluorophosphate resulted in the macrocycle shuttling to the axle NDI station which was manifested by a naked-eye detectable colour change in $\mathrm{CDCl}_{3}$ solution (Scheme 3). Detailed NMR studies of rotaxanes $60 \mathrm{a}, \mathbf{6 0 b}$ and their noninterlocked analogues allowed for the estimation of station occupancy by the macrocycle component in the presence of $\mathrm{Cl}^{-}, \mathrm{I}^{-}$and $\mathrm{PF}_{6}{ }^{-}$in various solvent mixtures. In $\mathrm{CDCl}_{3}$ triazolium station was occupied almost $100 \%$ in complexes of $60 \mathrm{a}$ and $60 \mathrm{~b}$ with $\mathrm{Cl}^{-}$and $\mathrm{I}^{-}$. Exchange for $\mathrm{PF}_{6}{ }^{-}$led to $62 \%$ occupancy of the NDI station for the XB rotaxane, but only $24 \%$ in the case of the $\mathrm{HB}$ rotaxane. Increasing polarity of solvent hampered anion binding, therefore in $\mathrm{CDCl}_{3} / \mathrm{CD}_{3} \mathrm{OD} 1: 1$ solutions of $60 \mathrm{a} \cdot \mathrm{Cl}, 60 \mathrm{~b} \cdot 1$ and $60 \mathrm{a} \cdot \mathrm{Cl}$, NDI was the most occupied station and anion exchange to $\mathrm{PF}_{6}$ only led to a modest increase of NDI occupancy. Only in $6 \mathbf{6 b} \cdot \mathbf{I}$ complex the macrocycle resided mostly over the triazolium station. These results clearly demonstrated that the $X B$ rotaxane switch was a superior example of synthetic molecular shuttle over its $\mathrm{HB}$ analogue in both $\mathrm{CDCl}_{3}$ and $\mathrm{CDCl}_{3} / \mathrm{CD}_{3} \mathrm{OD}$ solvent mixtures.

Two NDI and two triazolium stations were incorporated in the axle component of [3] rotaxanes $61 \mathbf{a} \cdot 2 \mathrm{PF}_{6}$ and $61 \mathbf{b} \cdot 2 \mathrm{PF}_{6}$ (Scheme 4). ${ }^{85}$ Similar to $60 \mathbf{a}-\mathbf{b}$, exchange of $\mathrm{PF}_{6}{ }^{-}$for chloride led to the two macrocycles shuttling from the NDI to the triazolium moieties causing a colour change of solution. Interestingly, anion association constant values for $\mathrm{XB}$ rotaxane $61 \mathrm{a} \cdot 2 \mathrm{PF}_{6}$ were significantly higher than for $\mathrm{HB}$ rotaxane $\mathbf{6 1 b} \cdot 2 \mathrm{PF}_{6}$ in $1: 1$ $\mathrm{CDCl}_{3} / \mathrm{CD}_{3} \mathrm{OD}$ and the $\mathrm{XB}$ host system exhibited an enhanced association strength of oxoanions over the $\mathrm{HB}$ system. Moreover, both rotaxanes exhibited the rare selectivity for $\mathrm{NO}_{3}-$ over acetate, bicarbonate, dihydrogen phosphate and notably chloride, resulting from a distinctive binding mode in which nitrate is bound in a sandwich-like complex between the two macrocycles (Scheme 4).

The above design was further extended in [3]rotaxane $62 \cdot 2 \mathrm{PF}_{6}$ by incorporation of $\mathrm{C}_{60}$ fullerene, a strong electron acceptor with redox properties, in the centre of the axle (Fig. 27). ${ }^{86}$ Additionally, isophthalamide macrocycles were appended by a ferrocene group, which is a strong electron donor. This elaborate interlocked system was demonstrated to adopt two distinct anion-dependent co-conformations that interconvert via translational motion of both ferrocenyl macrocycles between the peripheral NDI and central triazolium-bridged $\mathrm{C}_{60}$ axle stations. Anion exchange of $\mathrm{PF}_{6}{ }^{-}$for $\mathrm{Cl}^{-}$triggered a nakedeye switch-on response due to the macrocycles shuttling to the centre of the axle. This change precluded electron transfer to $\mathrm{NDI}$, causing an increase of NDI fluorescence emission and concomitant formation of a $\mathrm{C}_{60}$ fullerene-based chargeseparated state. Ultimately, selectivity of the initially populated charge-separated state in [3] rotaxane $62 \cdot 2 \mathrm{PF}_{6}$ was enabled by anion-induced co-conformational changes causing unprecedented alteration of communication pathways operating between the electron donor and acceptor motifs.

[3]Catenane $63 \cdot 2 \mathrm{PF}_{6}$ consisted of a large macrocycle incorporating two triazolium stations and tetrachlorofunctionalized perylene diimide (PDI). ${ }^{87}$ Similar to NDI, PDI is an electron deficient scaffold with excellent chromophoric, emissive, redox properties and a strong tendency to aggregate. However, tetrachlorination of PDI bay positions introduces steric bulk that forces the aromatic framework to twist from planarity, limiting aggregation. The smaller isophthalamide macrocycles of catenane $63 \cdot 2 \mathrm{PF}_{6}$ could not pass over either the twisted PDI or bulky tetraphenyl spacer unit and so their position was restricted to one half of the larger central ring. Exchange of $\mathrm{PF}_{6}-$ for chloride in $\mathrm{CDCl}_{3} / \mathrm{CD}_{3} \mathrm{OD}$ 3:1 caused 


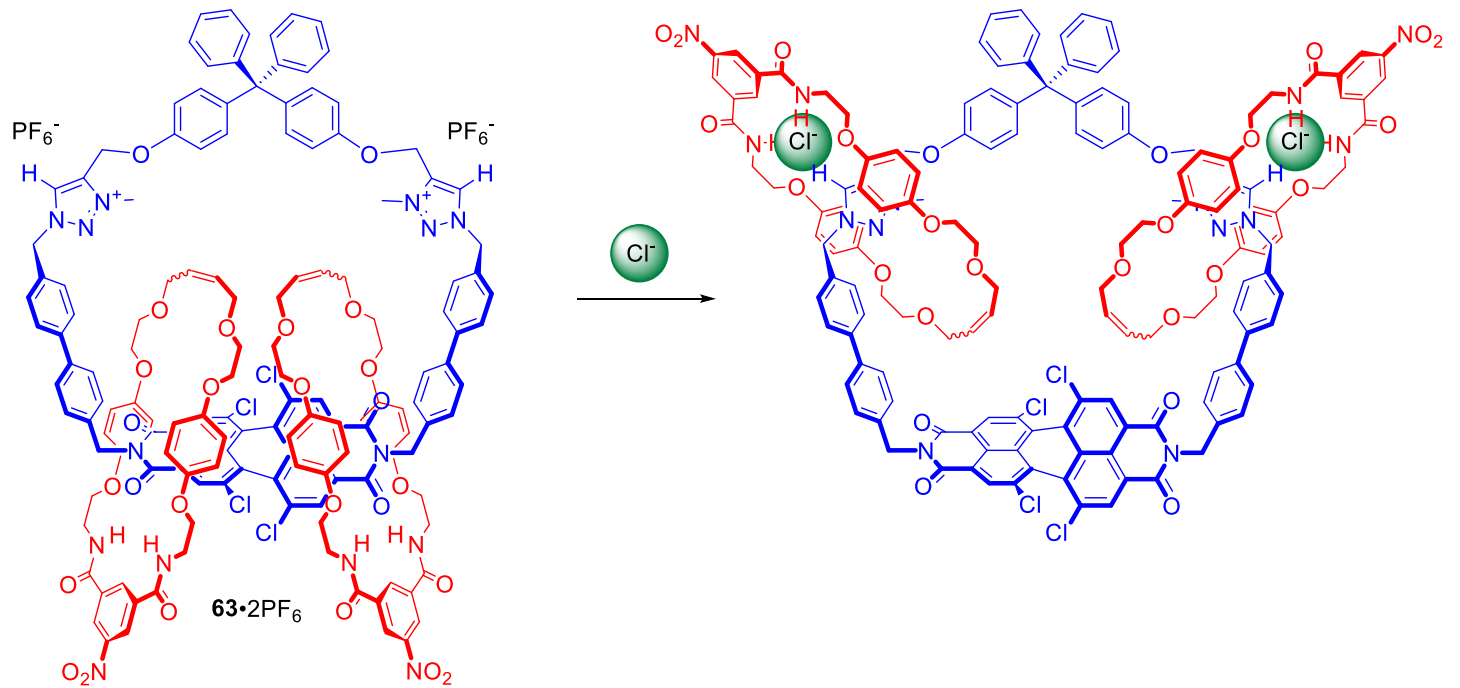

Scheme 5 Chloride-driven shuttling of [3]catenane.
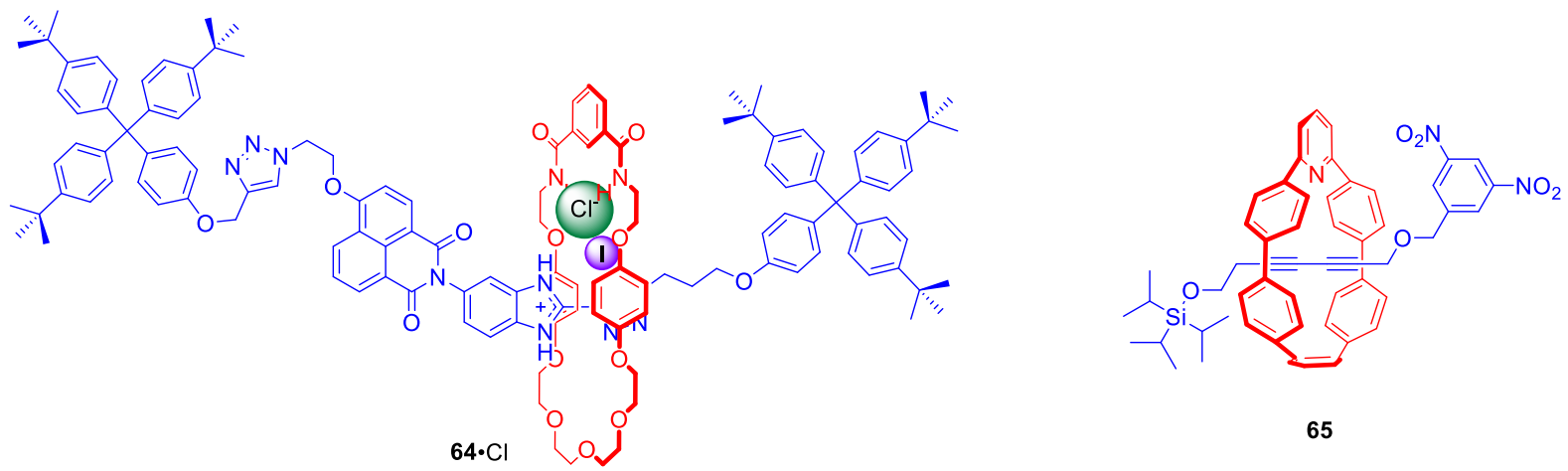

65

Figure 28 Anion sensitive fluorescent rotaxanes.

circumrotary motion of the smaller macrocyclic rings from the PDI motif to the two triazolium groups (Scheme 5). Dynamic behaviour of this unique system enabled colorometric and fluorescence anion sensing in $\mathrm{CHCl}_{3} / \mathrm{CH}_{3} \mathrm{OH} / \mathrm{H}_{2} \mathrm{O}$ 45:45:10.

[2] Rotaxane 64. $\mathrm{PF}_{6}$ was a relatively simple interlocked system containing a halogen bonding benzimidazoleiodotriazole station directly conjugated to a naphthalamide station in the axle component (Fig. 28). ${ }^{88}$ In its neutral state, the macrocyclic component resided over the axle naphthalamide group. Protonation of the benzimidazole moiety and subsequent addition of chloride led to translocation of the macrocycle towards the benzimidazolium-iodotriazole station due to anion coordination by halogen and hydrogen bond donors. This change of co-conformation could be observed via naked-eye colour change of solution, as well as an increase in fluorescence emission intensity.

Anion sensing MIMs do not always rely on recognition using weak interactions. Jasti et al. obtained, via AMT, [2] rotaxane 65 with fluorescent pyridyl-embedded cycloparaphenylene motif and the axle stoppered with a fluorescent quenching 3,5-dinitro phenyl group at the one end and fluoride-cleveable triisoproylsilyl group on the other. ${ }^{89}$ Addition of 1 equivalent of $\mathrm{TBA}^{+} \mathrm{F}^{-}$to a solution of rotaxane in chloroform led to a dramatic 123-fold increase in emission intensity due to the dethreading of the macrocycle from the destoppered axle. Although such a chemodosimeter is not reversible, it provided a sensitive method for $\mathrm{F}^{-}$sensing.

\section{Mechanically Interlocked Molecules for Ion-Pair Recognition and Sensing}

Ion-pair receptors are designed to combine the functionalities of cation and anion receptors for cooperative binding. ${ }^{90-92}$ This increases the synthetic complexity of the host structure which may be the reason behind the scarcity of ion-pair binding MIMs.

66 was the first example of a neutral heteroditopic rotaxane host system capable of binding alkali metal halides as axleseparated ion-pairs (Scheme 5). ${ }^{93}$ Its macrocyclic component consisted of a calix[4]diquinone cation recognition site covalently linked to an isophthalamide anion binding motif, while the axle component consisted of a bis-amide pyridine $\mathrm{N}$ oxide moiety. In the presence of sodium cation, rotaxane $\mathbf{6 6}$ adapted a co-conformation in which $\mathrm{Na}^{+}$was bound by calix[4]diquinone and the oxygen atom of $\mathrm{N}$-oxide (Scheme 6). This resulted in the formation of a binding cavity containing four amide $\mathrm{NH}$ groups. Removal of the sodium cation induced a pirouetting motion of the macrocycle due to formation of hydrogen bonds between the bis-amide group of the 


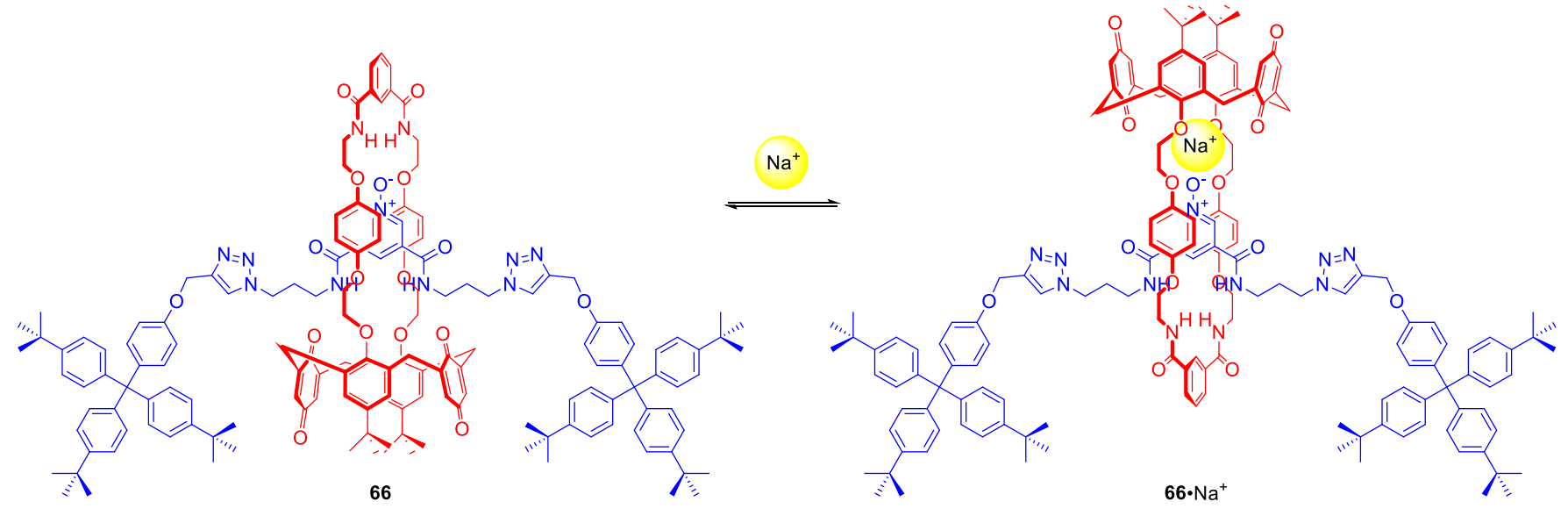

Scheme 6 Sodium-driven pirouetting motion of ion pair binding [2]rotaxane.

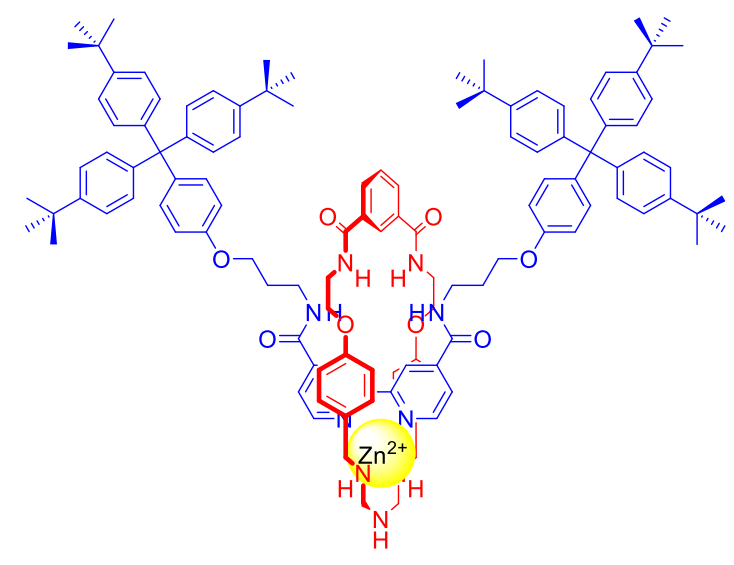

$67 \cdot \mathrm{Zn}^{2+}$

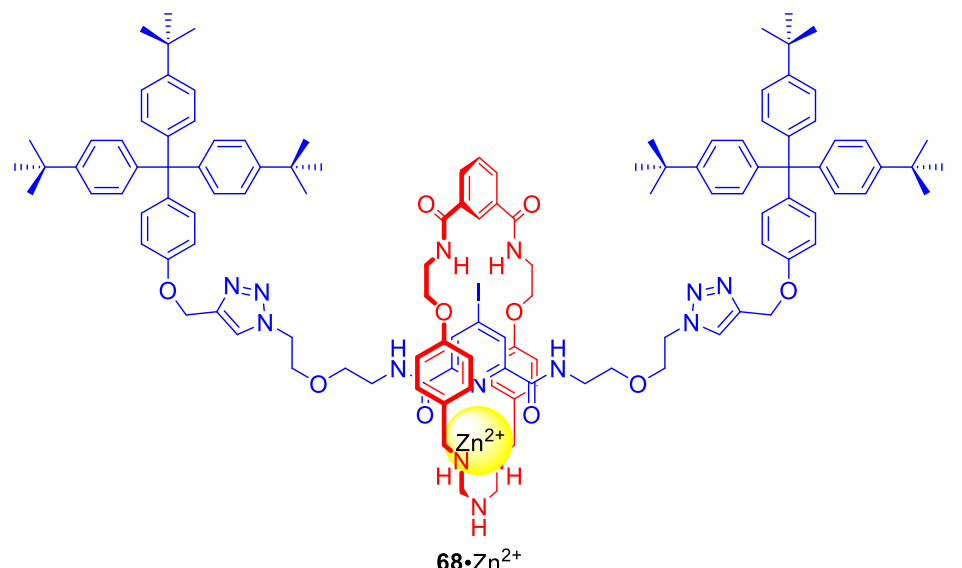

$68 \cdot \mathrm{Zn}^{2+}$

Figure 29 lon pair binding [2]rotaxanes.
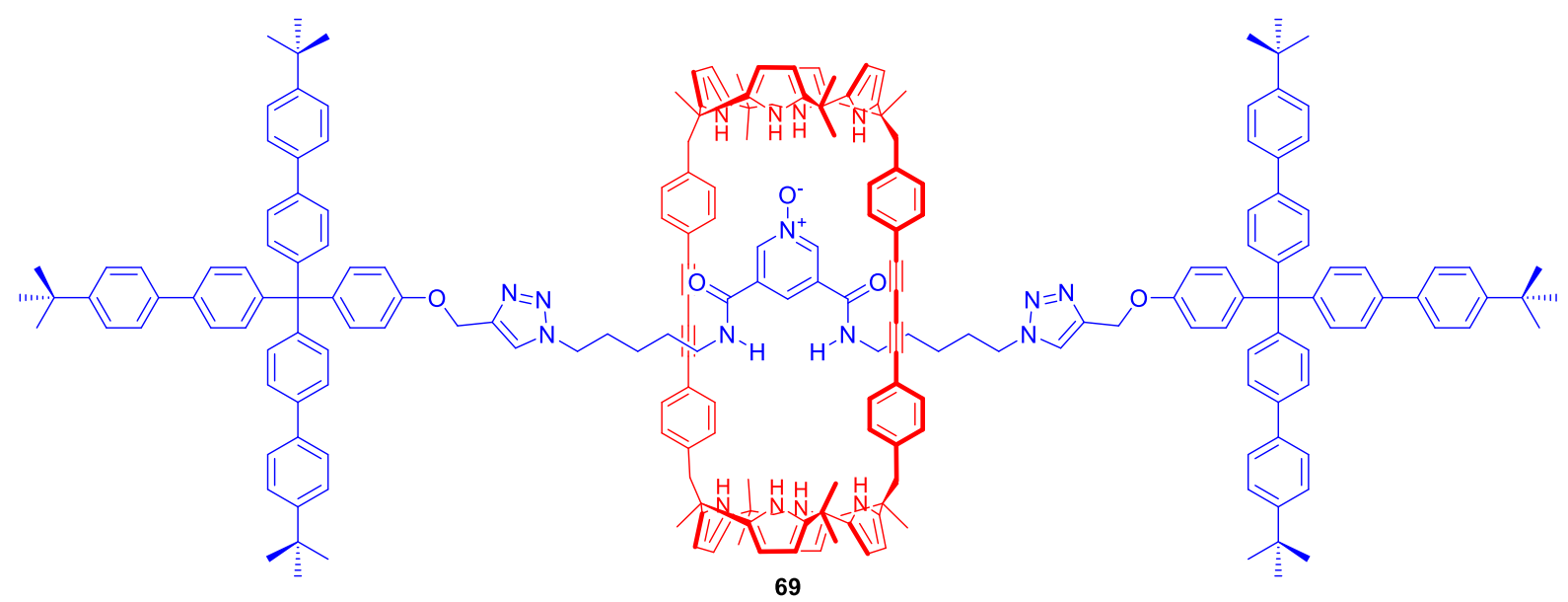

Figure 30 Ballester's ion pair binding [2]rotaxane. 
macrocycle and the $\mathrm{N}$-oxide group of the axle. Such behaviour was responsible for remarkable cooperativity factors for chloride and bromide binding in the presence of sodium in $\mathrm{CDCl}_{3} / \mathrm{CD}_{3} \mathrm{OD} 4: 1$ solution. A similar approach to the design of MIM ion pair receptors led to rotaxanes 67 and 68 which were able to complex $\mathrm{Zn}^{2+}$ and various anions in competitive solvent mixture: $\mathrm{CDCl}_{3} / \mathrm{CD}_{3} \mathrm{OD} / \mathrm{D}_{2} \mathrm{O}$ 45:45:10.94

Ballester and co-workers obtained [2] rotaxane 69 which also incorporated a bis-amide pyridine $\mathrm{N}$-oxide moiety in the axle and bis(calix[4]pyrrole) as the macrocyclic component. ${ }^{95}$ In chloroform solution, rotaxane $\mathbf{6 9}$ functioned as a heteroditopic receptor for tetraalkylammonium salts of chloride, nitrate and cyanate forming 1:1 complexes in which cation and anion were separated by the macrocyclic component.

\section{Conclusions}

Mechanically interlocked molecules have proved to be excellent platforms for the construction of ion binding receptors and sensors due to the unique properties of their mechanically bonded cavities. The increasing number of synthetic approaches makes MIMs more and more available.

In particular active metal templation has emerged recently as a useful methodology leading to both transition metal cation and anion binding MIMs. On the other hand the anion template strategy has evolved over the last 20 years from a mere curiosity to a versatile tool allowing for the synthesis of elaborate structures capable of anion recognition, sensing and shuttling. In more recent years the incorporation of halogen bond donors into interlocked structures have resulted in MIM host systems capable of anion binding in water with enhanced thermodynamic stability and selectivity in comparison to $\mathrm{HB}$ MIM and non-interlocked host analogues.

However, the full potential of ion binding MIMs has yet to be realised. For example, only recently have the unique spatial properties of the mechanical bond begun to be explored in enantioselective recognition. The integration of chiral groups into MIM binding cavities or exploitation of chirality arising from the mechanical bond is still rare, and such host systems have the potential to demonstrate enhanced chiral recognition and to play an important role in asymmetric catalysis. In addition, the application of MIM hosts for extraction and membrane transport applications are areas to be investigated. Moreover, the increasing number of ion recognition driven shuttling MIMs illustrate the exciting future development of sophisticated responsive nanotechnological devices and materials.

\section{Conflicts of interest}

There are no conflicts to declare.

\section{Acknowledgements}

KMB thanks the EPSRC for postdoctoral funding (EPSRC grant number EP/P033490/1). The authors thank Dr. Jessica Pancholi and Andrew Docker, University of Oxford, for helpful discussions.

\section{Notes and references}

1 C. J. Bruns and J. F. Stoddart, The Nature of the Mechanical Bond: From Molecules to Machines, John Wiley \& Sons, Inc., Hoboken, New Jersey, 2016.

2 J. F. Stoddart, Chem. Soc. Rev., 2009, 38, 1802.

3 E. A. Neal and S. M. Goldup, Chem. Commun., 2014, 50, 5128.

4 M. Xue, Y. Yang, X. Chi, X. Yan and F. Huang, Chem. Rev., 2015, $115,7398$.

5 S. Erbas-Cakmak, D. A. Leigh, C. T. McTernan and A. L. Nussbaumer, Chem. Rev., 2015, 115, 10081.

6 G. Gil-Ramírez, D. A. Leigh and A. J. Stephens, Angew. Chem. Int. Ed., 2015, 54, 6110

7 J. E. M. Lewis, M. Galli and S. M. Goldup, Chem. Commun., 2017, 53, 298.

8 S. Kassem, T. van Leeuwen, A. S. Lubbe, M. R. Wilson, B. L. Feringa and D. A. Leigh, Chem. Soc. Rev., 2017, 46, 2592.

9 M. R. Wilson, J. Solà, A. Carlone, S. M. Goldup, N. Lebrasseur and D. A. Leigh, Nature, 2016, 534, 235.

10 S. Erbas-Cakmak, S. D. P. Fielden, U. Karaca, D. A. Leigh, C. T. McTernan, D. J. Tetlow and M. R. Wilson, Science, 2017, 358, 340.

11 J. D. Crowley, S. M. Goldup, A.-L. Lee, D. A. Leigh and R. T. McBurney, Chem. Soc. Rev., 2009, 38, 1530.

12 K. D. Hänni and D. A. Leigh, Chem. Soc. Rev., 2010, 39, 1240.

13 J. E. Beves, B. A. Blight, C. J. Campbell, D. A. Leigh and R. T. McBurney, Angew. Chem. Int. Ed., 2011, 50, 9260.

14 J. E. M. Lewis, P. D. Beer, S. J. Loeb and S. M. Goldup, Chem. Soc. Rev., 2017, 46, 2577.

15 M. Denis and S. M. Goldup, Nat. Rev. Chem., 2017, 1, 0061.

16 G. T. Spence and P. D. Beer, Acc. Chem. Res., 2013, 46, 571.

17 M. J. Chmielewski, J. J. Davis and P. D. Beer, Org. Biomol. Chem., 2009, 7, 415.

18 M. J. Langton and P. D. Beer, Acc. Chem. Res., 2014, 47, 1935.

19 N. H. Evans and P. D. Beer, Chem. Soc. Rev., 2014, 43, 4658.

20 A. Caballero, F. Zapata and P. D. Beer, Coord. Chem. Rev., 2013, 257, 2434.

21 C. O. Dietrich-Buchecker, J. P. Sauvage and J. P. Kintzinger, Tetrahedron Lett., 1983, 24, 5095.

22 V. Aucagne, K. D. Hänni, D. A. Leigh, P. J. Lusby and D. B. Walker, J. Am. Chem. Soc., 2006, 128, 2186.

23 M. Cirulli, A. Kaur, J. E. M. Lewis, Z. Zhang, J. A. Kitchen, S. M. Goldup and M. M. Roessler, J. Am. Chem. Soc., 2019, 141, 879.

24 C. Dietrich-Buchecker, J. P. Sauvage and J. M. Kern, J. Am. Chem. Soc., 1989, 111, 7791.

25 G. Baggi and S. J. Loeb, Angew. Chem. Int. Ed., 2016, 55, 12533.

26 G. Baggi and S. J. Loeb, Chem. Eur. J., 2017, 23, 14163.

27 M. Denis, J. Pancholi, K. Jobe, M. Watkinson and S. M. Goldup, Angew. Chem. Int. Ed., 2018, 57, 5310.

28 T. Shukla, A. K. Dwivedi, R. Arumugaperumal, C.-M. Lin, S.-Y. Chen and H.-C. Lin, Dyes Pigm., 2016, 131, 49.

29 S.-M. Chan, F.-K. Tang, C.-S. Kwan, C.-Y. Lam, S. C. K. Hau and K. C. F. Leung, Mater. Chem. Front., 2019, 3, 2388.

30 C. Lincheneau, B. Jean-Denis and T. Gunnlaugsson, Chem. Commun., 2014, 50, 2857.

31 F. Zapata, O. A. Blackburn, M. J. Langton, S. Faulkner and P. D. Beer, Chem. Commun., 2013, 49, 8157.

32 J. F. Ayme, G. Gil-Ramírez, D. A. Leigh, J. F. Lemonnier, A. Markevicius, C. A. Muryn and G. Zhang, J. Am. Chem. Soc., 2014, 136, 13142.

33 G. Zhang, G. Gil-Ramírez, A. Markevicius, C. Browne, I. J. Vitorica- 
Yrezabal and D. A. Leigh, J. Am. Chem. Soc., 2015, 137, 10437.

34 M. Nandi, S. Bej, T. K. Ghosh and P. Ghosh, Chem. Commun., 2019, 55, 3085.

35 R. Mitra, M. Thiele, F. Octa-Smolin, M. C. Letzel and J. Niemeyer, Chem. Commun., 2016, 52, 5977.

36 S. Hoekman, M. O. Kitching, D. A. Leigh, M. Papmeyer and D. Roke, J. Am. Chem. Soc., 2015, 137, 7656.

37 M. Galli, J. E. M. Lewis and S. M. Goldup, Angew. Chem. Int. Ed., 2015, 54, 13545.

38 A. Heard and S. Goldup, ChemRxiv, 2019, preprint, DOI:10.26434/chemrxiv.9701789.v1.

39 Y. J. Lee, K. S. Liu, C. C. Lai, Y. H. Liu, S. M. Peng, R. P. Cheng and S. H. Chiu, Chem. Eur. J., 2017, 23, 9756.

40 N. Busschaert, C. Caltagirone, W. Van Rossom and P. A. Gale, Chem. Rev., 2015, 115, 8038.

41 N. H. Evans and P. D. Beer, Angew. Chem. Int. Ed., 2014, 53, 11716.

42 J. A. Wisner, P. D. Beer and M. G. B. Drew, Angew. Chem. Int. Ed., 2001, 40, 3606.

43 L. C. Gilday, S. W. Robinson, T. A. Barendt, M. J. Langton, B. R. Mullaney and P. D. Beer, Chem. Rev., 2015, 115, 7118.

44 A. Brown and P. D. Beer, Chem. Commun., 2016, 52, 8645.

45 J. Y. C. Lim and P. D. Beer, Chem, 2018, 4, 731.

46 S. Kubik, Chem. Soc. Rev., 2010, 39, 3648.

47 M. J. Langton, C. J. Serpell and P. D. Beer, Angew. Chem. Int. Ed., 2016, 55, 1974.

48 S. Kubik, Acc. Chem. Res., 2017, 50, 2870.

49 M. A. Yawer, V. Havel and V. Sindelar, Angew. Chem. Int. Ed., 2015, 54, 276.

50 M. J. Langton and P. D. Beer, Chem. Commun., 2014, 50, 8124

51 V. Martí-Centelles and P. D. Beer, Chem. Eur. J., 2015, 21, 9397.

52 M. J. Langton, O. A. Blackburn, T. Lang, S. Faulkner and P. D. Beer, Angew. Chem. Int. Ed., 2014, 53, 11463.

53 N. G. White, A. R. Colaço, I. Marques, V. Félix and P. D. Beer, Org. Biomol. Chem., 2014, 12, 4924.

54 J. Y. C. Lim, M. J. Cunningham, J. J. Davis and P. D. Beer, Dalton Trans., 2014, 43, 17274.

55 A. Brown, M. J. Langton, N. L. Kilah, A. L. Thompson and P. D. Beer, Chem. Eur. J., 2015, 21, 17664.

56 M. Denis, L. Qin, P. Turner, K. Jolliffe and S. M. Goldup, Angew. Chem. Int. Ed., 2018, 57, 5315.

57 S. J. Pike, J. J. Hutchinson and C. A. Hunter, J. Am. Chem. Soc., 2017, 139, 6700.

58 A. Brown, T. Lang, K. M. Mullen and P. D. Beer, Org. Biomol. Chem., 2017, 15, 4587.

59 J. P. Byrne, S. Blasco, A. B. Aletti, G. Hessman and T. Gunnlaugsson, Angew. Chem. Int. Ed., 2016, 55, 8938.

60 N. L. Kilah, M. D. Wise, C. J. Serpell, A. L. Thompson, N. G. White, K. E. Christensen and P. D. Beer, J. Am. Chem. Soc., 2010, 132, 11893.

61 J. M. Mercurio, R. C. Knighton, J. Cookson and P. D. Beer, Chem. Eur. J., 2014, 20, 11740.

62 A. E. Hess and P. D. Beer, Org. Biomol. Chem., 2016, 14, 10193.

63 J. M. Mercurio, A. Caballero, J. Cookson and P. D. Beer, RSC Adv., 2015, 5, 9298.

64 M. J. Langton, S. W. Robinson, I. Marques, V. Felix and P. D. Beer, Nat. Chem., 2014, 6, 1039.

65 M. Řezanka, M. J. Langton and P. D. Beer, Chem. Commun., 2015, 51, 4499.

66 M. J. Langton, I. Marques, S. W. Robinson, V. Félix and P. D. Beer, Chem. Eur. J., 2016, 22, 185.

67 T. Bunchuay, A. Docker, A. J. Martinez-Martinez and P. D. Beer, Angew. Chem. Int. Ed., 2019, 58, 13823.

68 S. W. Robinson, C. L. Mustoe, N. G. White, A. Brown, A. L. Thompson, P. Kennepohl and P. D. Beer, J. Am. Chem. Soc., 2015, 137, 499.

69 S. W. Robinson and P. D. Beer, Org. Biomol. Chem., 2017, 15, 153.

70 J. Y. C. Lim, I. Marques, V. Félix and P. D. Beer, Angew. Chem. Int.
Ed., 2018, 57, 584.

71 H. A. Klein and P. D. Beer, Chem. Eur. J., 2019, 25, 3125.

72 L. C. Gilday and P. D. Beer, Chem. Eur. J., 2014, 20, 8379.

73 B. R. Mullaney, B. E. Partridge and P. D. Beer, Chem. Eur. J., 2015, 21, 1660.

74 X. Li, J. Y. C. Lim and P. D. Beer, Chem. Eur. J., 2018, 24, 17788.

75 J. Y. C. Lim, I. Marques, A. L. Thompson, K. E. Christensen, V. Félix and P. D. Beer, J. Am. Chem. Soc., 2017, 139, 3122.

76 A. Caballero, F. Zapata, N. G. White, P. J. Costa, V. Félix and P. D. Beer, Angew. Chem. Int. Ed., 2012, 51, 1876.

77 B. R. Mullaney, A. L. Thompson and P. D. Beer, Angew. Chem. Int. Ed., 2014, 53, 11458.

78 M. J. Langton, Y. Xiong and P. D. Beer, Chem. Eur. J., 2015, 21, 18910.

79 X. Li, J. Y. C. Lim and P. D. Beer, Faraday Discuss., 2017, 203, 245.

80 J. Y. C. Lim, T. Bunchuay and P. D. Beer, Chem. Eur. J., 2017, 23, 4700.

81 J. Y. C. Lim and P. D. Beer, Eur. J. Org. Chem., 2019, 2019, 3433.

82 J. Y. C. Lim, I. Marques, V. Félix and P. D. Beer, J. Am. Chem. Soc., 2017, 139, 12228.

83 A. Caballero, L. Swan, F. Zapata and P. D. Beer, Angew. Chem. Int. Ed., 2014, 53, 11854.

84 T. A. Barendt, S. W. Robinson and P. D. Beer, Chem. Sci., 2016, 7, 5171.

85 T. A. Barendt, A. Docker, I. Marques, V. Félix and P. D. Beer, Angew. Chem. Int. Ed., 2016, 55, 11069.

86 T. A. Barendt, I. Rašović, M. A. Lebedeva, G. A. Farrow, A. Auty, D. Chekulaev, I. V. Sazanovich, J. A. Weinstein, K. Porfyrakis and P. D. Beer, J. Am. Chem. Soc., 2018, 140, 1924.

87 T. A. Barendt, L. Ferreira, I. Marques, V. Felix and P. D. Beer, J. Am. Chem. Soc., 2017, 139, 9026.

88 H. A. Klein, H. Kuhn and P. D. Beer, Chem. Commun., 2019, 55, 9975.

89 J. M. Van Raden, B. M. White, L. N. Zakharov and R. Jasti, Angew. Chem. Int. Ed., 2019, 58, 7341.

90 S. K. Kim and J. L. Sessler, Chem. Soc. Rev., 2010, 39, 3784.

91 A. J. McConnell and P. D. Beer, Angew. Chem. Int. Ed., 2012, 51, 5052.

92 Q. He, G. I. Vargas-Zúñiga, S. H. Kim, S. K. Kim and J. L. Sessler, Chem. Rev., 2019, 119, 9753.

93 R. C. Knighton and P. D. Beer, Chem. Commun., 2014, 50, 1540.

94 A. Brown, K. M. Mennie, O. Mason, N. G. White and P. D. Beer, Dalton Trans., 2017, 46, 13376.

95 J. R. Romero, G. Aragay and P. Ballester, Chem. Sci., 2017, 8, 491. 